\title{
EFFECTS OF THE POLY(ADP-RIBOSE) POLYMERASE INHIBITOR OLAPARIB IN CERULEIN-INDUCED PANCREATITIS
}

\author{
Akbar Ahmad, ${ }^{*}$ Aline Haas De Mello, ${ }^{*}$ Bartosz Szczesny, ${ }^{*}$ Gábor Törö, ${ }^{*}$ \\ Michela Marcatti, ${ }^{*}$ Nadiya Druzhyna, ${ }^{*}$ Lucas Liaudet, ${ }^{\dagger}$ Stefano Tarantini, ${ }^{\ddagger}$ \\ Reinaldo Salomao, \$ Francisco Garcia Soriano," and Csaba Szabo*ף \\ *Department of Anesthesiology, The University of Texas Medical Branch at Galveston, Galveston, Texas; \\ ${ }^{\dagger}$ Department of Intensive Care Medicine and Burns, Lausanne University Hospital Medical Center, \\ Lausanne, Switzerland; ${ }^{\ddagger}$ Department of Geriatric Medicine, Reynolds Oklahoma Center on Aging, \\ University of Oklahoma Health Sciences Center, Oklahoma City, Oklahoma; ${ }^{\text {SDivision }}$ of Infectious \\ Diseases, Department of Medicine, Hospital São Paulo, Escola Paulista de Medicina, Universidade \\ Federal de São Paulo, São Paulo, Brazil;" Laboratório de Investigação Médica_Faculdade de Medicina \\ da Universidade de São Paulo, São Paulo, Brazil; and "Chair of Pharmacology, Faculty of Science and \\ Medicine, University of Fribourg, Fribourg, Switzerland
}

\begin{abstract}
Objective: Activation of the constitutive nuclear and mitochondrial enzyme poly (ADP-ribose) polymerase (PARP) has been implicated in the pathogenesis of cell dysfunction, inflammation, and organ failure in various forms of critical illness. The objective of our study was to evaluate the efficacy and safety of the clinically approved PARP inhibitor olaparib in an experimental model of pancreatitis in vivo and in a pancreatic cell line subjected to oxidative stress in vitro. The preclinical studies were complemented with analysis of clinical samples to detect PARP activation in pancreatitis. Methods: Mice were subjected to cerulein-induced pancreatitis; circulating mediators and circulating organ injury markers; pancreatic myeloperoxidase and malondialdehyde levels were measured and histology of the pancreas was assessed. In human pancreatic duct epithelial cells (HPDE) subjected to oxidative stress, PARP activation was measured by PAR Western blotting and cell viability and DNA integrity were quantified. In clinical samples, PARP activation was assessed by PAR (the enzymatic product of PARP) immunohistochemistry. Results: In male mice subjected to pancreatitis, olaparib $(3 \mathrm{mg} / \mathrm{kg}$ i.p.) improved pancreatic function: it reduced pancreatic myeloperoxidase and malondialdehyde levels, attenuated the plasma amylase levels, and improved the histological picture of the pancreas. It also attenuated the plasma levels of proinflammatory mediators (TNF- $\alpha$, IL-1 $\beta$, IL-2, IL-4, IL-6, IL-12, IP-10, KC) but not MCP-1, RANTES, or the anti-inflammatory cytokine IL-10. Finally, it prevented the slight, but significant increase in plasma blood urea nitrogen level, suggesting improved renal function. The protective effect of olaparib was also confirmed in female mice. In HPDE cells subjected to oxidative stress olaparib $(1 \mu \mathrm{M})$ inhibited PARP activity, protected against the loss of cell viability, and prevented the loss of cellular $\mathrm{NAD}^{+}$levels. Olaparib, at $1 \mu \mathrm{M}$ to $30 \mu \mathrm{M}$ did not have any adverse effects on DNA integrity. In human pancreatic samples from patients who died of pancreatitis, increased accumulation of PAR was demonstrated. Conclusion: Olaparib improves organ function and tempers the hyperinflammatory response in pancreatitis. It also protects against pancreatic cell injury in vitro without adversely affecting DNA integrity. Repurposing and eventual clinical introduction of this clinically approved PARP inhibitor may be warranted for the experimental therapy of pancreatitis.
\end{abstract}

KEYWORDS—Cell death, DNA, mitochondria, multiorgan dysfunction, pancreatitis, shock

ABBREVIATIONS_ALB_albumin; ALT_alanine aminotransferase; AMY - amylase; BUN_blood urea nitrogen; $\mathrm{Ca}^{2+}$ total calcium; $\mathrm{CRE} —$ creatinine; $\mathrm{GLU} —$ glucose; $\mathrm{K}^{+}$—potassium; MDA—malondialdehyde; MPO—myeloperoxidase; $\mathrm{Na}^{+}$— sodium; PAR—poly(ADP-ribose); PARP_poly(ADP-ribose) polymerase; PHOS_phosphorus

\section{INTRODUCTION}

Acute pancreatitis remains a life-threatening disease affecting several million people annually worldwide. In the United States, the rate of primary discharge diagnosis for acute pancreatitis is more than 80 per 100,000 US adults per year. In-hospital case fatality is approximately $1 \%$, but in subjects that are older than 65 years, it is several times higher. In the USA, in 2009, over 270,000 acute pancreatitis patients were diagnosed: thus, acute pancreatitis is one of the most common
Address reprint requests to Csaba Szabo, MD, $\mathrm{PhD}$, Chair of Pharmacology, Faculty of Science and Medicine, University of Fribourg, Chemin du Musée 18, Fribourg 1700, Switzerland. E-mail: csaba.szabo@unifr.ch.

The current report does not contain human interventional studies. (The human pancreatic tissue samples were obtained from a commercial biobank which obtained them under informed consent and in compliance with all applicable rules and regulations.)

The current report does not contain human studies or studies that would require consenting

The datasets during and/or analyzed during the current study are available from the corresponding author on reasonable request.

AA conducted in vivo and in vitro experiments; BS, GT, ND, and MM conducted in vitro studies, CS, LL, FGS, and RS conceived the overall study design; AA, ST, LL,
FGS, and RS contributed to various parts of the study design, method development, data interpretation, and writing of the manuscript. CS was responsible for the coordination of the project. CS drafted the first version of the manuscript and finalized the manuscript. All authors read and approved the final manuscript.

This work was supported by grants from the National Institutes of Health (R01GM107876) and the Swiss National Foundation (to CS), and by the FAPESP (to RS and FGS).

The authors report no conflicts of interest.

Supplemental digital content is available for this article. 
gastrointestinal diseases that requires acute hospitalization. Treatment costs of the disease are estimated over $\$ 2.5$ billion/yr $(1,2)$. Despite extensive research and despite a large number of pivotal clinical trials targeting various mechanisms of the disease, no specific pharmacological or immunological therapies are available for the treatment of this condition; the mainstays of therapy remain supportive care such as fluid, nutrition, and the clinical management of complications (1-3).

Poly(ADP-ribose) polymerase (PARP) is a constitutive nuclear and mitochondrial enzyme with multiple regulatory functions in health and disease (4-10). Pathological overactivation of PARP has been implicated in many forms of critical illness (4-10), including pancreatitis (11-17). Pharmacological PARP inhibitors of various structural classes as well as PARP-1-deficient mice were shown to exert beneficial effects in various animal models of pancreatitis (11-17). Although these data suggest that PARP may be a therapeutic target in pancreatitis, translational advancement of this concept was not possible, because-until recently-there were no clinically approved drugs to inhibit PARP. This situation, however, has changed, due to an independent line of work in the field of oncology, which demonstrated that in certain forms of cancer, PARP inhibitors can provide therapeutic benefit. This work revitalized the pharmaceutical industry's interest in PARP inhibitors, and as a consequence, in recent years, several classes of PARP inhibitors have been approved by various regulatory agencies worldwide and have entered routine clinical practice - in the field of oncology $(18,19)$. One of these clinically approved PARP inhibitors is olaparib (Lynparza). It is a competitive PARP inhibitor that inhibits the binding of the substrate of PARP $\left(\mathrm{NAD}^{+}\right)$into the active site of the enzyme.

In our recent position paper (20) we have outlined an approach for the therapeutic repurposing of clinically approved PARP inhibitors for various nononcological indications. Various forms of critical illness are prime candidates for repurposing, because the available therapeutic options are limited, the expected duration of drug therapy is relatively short, and the body of preclinical data - at least conceptually — supports the validity of such efforts. However — as outlined in (20) — additional experiments are needed to expand the groundwork for this concept. Because each class of PARP inhibitors have different pharmacological properties, repurposing efforts require testing the exact same pharmacological inhibitor that would be a candidate for repurposing (as opposed to earlier generation inhibitors) and needs to focus both on efficacy and safety endpoints. The latter point is especially salient, because PARP activity has been implicated in DNA repair (4-10) and it needs to be ensured that the therapeutic benefit of PARP inhibitors in critical illness does not come at the expense of an impairment of DNA integrity.

The current study was set out to begin such a repurposing effort using the clinically approved PARP inhibitor olaparib for acute pancreatitis. From several clinically approved PARP inhibitors, olaparib was selected because several independent experiments have already demonstrated its beneficial effects in various nononcological conditions such as neuroinjury (21, 22), acute lung injury (23), cardiac reperfusion injury (24), liver injury (25), and various forms of systemic inflammation $(26,27)$.

Our in vivo experiments employed a widely accepted experimental model of pancreatitis (induced by cerulein). We have also conducted an in vitro sub-study (human pancreatic epithelial cells subjected to oxidative stress) both focusing on efficacy endpoints (cell viability) as well as safety endpoints (nuclear and mitochondrial DNA integrity). Our in vivo results demonstrate the efficacy of olaparib on local (pancreatic injury) and systemic (renal dysfunction) outcome variables in the pancreatitis model, while the in vitro results define the concentration range of the PARP inhibitor that exerts cytoprotective effects without adversely affecting DNA integrity. Thus, the data presented in the current report can be considered a potential first step for the future repurposing and clinical introduction of the PARP inhibitor olaparib for the experimental therapy of pancreatitis.

\section{MATERIALS AND METHODS}

\section{Materials}

Unless stated otherwise, all chemicals and reagents were obtained from Sigma-Aldrich (St. Louis, Missouri).

\section{Animals}

C57/BL6 (male and female, 2 mo old) were purchased from Jackson Laboratories. They were housed in a light-controlled room with a 12-h light-dark cycle and were allowed ad libitum access to food and water. All investigations adhered to the Guide for the Care and Use of Laboratory Animals published by the National Institutes of Health (Eighth Edition, 2011) and were performed in accordance with the IACUC, University of Texas Medical Branch, Galveston, Texas.

\section{Pancreatitis induced by cerulein}

Mice were randomly allocated into the following groups: Sham group: mice were treated hourly (five times) with saline solution, intraperitoneally [IP] instead of cerulein $(n=10)$; Cerulein group: mice were treated hourly $(\times 5)$ with cerulein $(50 \mu \mathrm{g} / \mathrm{kg}$, in saline, i.p. plus olaparib vehicle) $(\mathrm{n}=10)$; Cerulein + olaparib group: mice were treated hourly $(\times 5)$ with cerulein $(50 \mu \mathrm{g} / \mathrm{kg}$, in saline, IP) and received olaparib ( $3 \mathrm{mg} / \mathrm{kg}$, i.p.) 1 and $6 \mathrm{~h}$ after the first dosing of cerulein $(n=10)$. (The delay in the administration of olaparib relative to cerulein was introduced to mimic the clinical situation where pretreatment with the inhibitor is not realistic.) Mice were killed by exsanguination at $6 \mathrm{~h}$ after the first cerulein injection. Blood samples were obtained by intracardiac puncture. The pancreas was removed immediately, frozen in liquid nitrogen, and stored at $-80^{\circ} \mathrm{C}$ until assayed. Portions of these organs were also fixed in formaldehyde for histological examination.

\section{Myeloperoxidase assay}

Myeloperoxidase activity was measured in pancreas tissue homogenates using a commercially available myeloperoxidase (MPO) fluorometric detection kit (Enzo Life Sciences, Farmingdale, NY) as described (28). The assay utilizes a non-fluorescent detection reagent, which is oxidized in the presence of hydrogen peroxide and MPO to produce its fluorescent analog. The fluorescence was measured at excitation wavelength of $530 \mathrm{~nm}$ to $571 \mathrm{~nm}$ and emission wavelength of $590 \mathrm{~nm}$ to $600 \mathrm{~nm}$.

\section{Malondialdehyde assay}

Tissue malondialdehyde (MDA) levels, an index of cellular injury/oxidative stress, were quantified in pancreas homogenates using a fluorimetric MDAspecific lipid peroxidation assay kit (Enzo Life Sciences, Farmingdale, NY) as described (28). The assay is based on the BML-AK171 method in which two molecules of the chromogenic reagent $\mathrm{N}$-methyl-2-phenylindole react with one molecule of MDA at $45^{\circ} \mathrm{C}$ to yield a stable carbocyanine dye with a maximum absorption at $586 \mathrm{~nm}$. 


\section{Measurement of biochemical parameters of organ dysfunction}

Blood samples were collected via cardiac puncture and were analyzed by using a Vetscan analyzer (Abaxis North America, Union City, Calif) as described (26) for various biochemical parameters within $1 \mathrm{~h}$ of collection.

\section{Quantification of plasma cytokine levels}

Blood from all groups were collected in heparinized blood collection tubes, and centrifuged at $4{ }^{\circ} \mathrm{C}$ for $10 \mathrm{~min}$ at $1,000 \times \mathrm{g}$ within $30 \mathrm{~min}$ of collection. Plasma was isolated, aliquoted, and stored at $-80^{\circ} \mathrm{C}$ until use. The EMD Millipore's MILLIPLEX MAP Mouse cytokine Magnetic Bead Panel 1 kit was used for the simultaneous quantification of multiple circulating analytes (Merck Millipore, Darmstadt, Germany). Luminex uses a proprietary technique to internally color code microspheres with two fluorescent dyes and to create distinctly colored bead sets of $5005.6 \mu \mathrm{m}$ polystyrene microspheres or 80 $6.45 \mu \mathrm{m}$ magnetic microspheres, each of which is coated with a specific capture antibody. After an analyte from a test sample is captured by the bead, a biotinylated detection antibody is introduced. The reaction mixture is then incubated with streptavidin-phycoerythrin (PE) conjugate, the reporter molecule, to complete the reaction on the surface of each microsphere. The Luminex instrument acquires and analyzes data using the LuminexxMAP fluorescent detection method and the LuminexxPONENT acquisition software (Thermo Fisher Scientific, Waltham, Mass).

\section{Histological studies and TUNEL assay}

Pancreas sections were collected at $6 \mathrm{~h}$ after 1 st cerulein injection. They were fixed for 1 week in buffered formaldehyde solution (10\% in PBS) at room temperature, dehydrated by graded ethanol and embedded in Paraplast (Sherwood Medical, Mahwah, NJ). Tissue sections (thickness: $7 \mu \mathrm{m}$ ) were deparaffinized with xylene stained with hematoxylin/eosin and studied using light microscopy. Histological studies were performed in a blinded fashion. TUNEL assay was conducted using a TUNEL detection kit (ApopTag Peroxidase In Situ Apoptosis Detection Kit; EMD Millipore, Calif) according to the manufacturer's instruction.

\section{Cell culture}

Human Pancreatic Duct Epithelial Cells (HPDE) were purchased from the Kerafast, Inc (Catalog \# ECA001), and cultured in Keratinocyte Basal Medium (Lonza, Clonetics KBM, Catalog \# CC-3111) supplemented with $\times 1$ antibiotic_antimycotic (Gibco Catalog\# 15240062).

\section{In vitro oxidative stress induced by hydrogen peroxide}

HPDE cells $\left(20 \times 10^{3}\right.$ cells per well) were seeded overnight onto 96-well tissue culture plates with cell culture medium and cultured at $37^{\circ} \mathrm{C}$ at $5 \% \mathrm{CO}_{2}$ atmosphere for $24 \mathrm{~h}$. The cells were then placed in fresh cell culture medium and treated with olaparib $(1 \mu \mathrm{M}-100 \mu \mathrm{M})$ followed by hydrogen peroxide $\left(\mathrm{H}_{2} \mathrm{O}_{2}\right)(300 \mu \mathrm{M}-1 \mathrm{mM}, 1-24 \mathrm{~h})$ exposure

\section{MTT assay}

The MTT method was performed as described (28). Briefly, 3-(4,5dimethyl-2-thiazolyl)-2,5-diphenyl-2H-tetrazolium bromide (MTT) was added to the cells at a final concentration of $0.5 \mathrm{mg} / \mathrm{mL}$ and cells were cultured at $37^{\circ} \mathrm{C}$ for $1 \mathrm{~h}$. The cells were washed with PBS and the formazan dye was dissolved in DMSO. The amount of converted formazan dye was measured at $570 \mathrm{~nm}$ with a background measurement at $690 \mathrm{~nm}$ on a Power wave reader (Biotek).

\section{LDH assay}

Measurement of lactate dehydrogenase (LDH) release into the medium (28) was used to assess cytotoxicity. Briefly, $30 \mu \mathrm{L}$ of supernatant was collected and mixed with $100 \mu \mathrm{L}$ freshly prepared LDH assay reagent containing $85 \mathrm{mM}$ lactic acid, $1 \mathrm{mM}$ nicotinamide adenine dinucleotide $\left(\mathrm{NAD}^{+}\right), 0.27 \mathrm{mM} \mathrm{N}$-methyl phenazonium methyl sulfate (PMS), $0.528 \mathrm{mM}$ 2-(4-iodophenyl)-3-(4-nitrophenyl)-5-phenyl-2H-tetrazolium chloride (INT), and $200 \mathrm{mM}$ Tris (pH 8.2). The changes in absorbance were read kinetically at $492 \mathrm{~nm}$ for $15 \mathrm{~min}$ (kinetic $\mathrm{LDH}$ assay) on a monochromator-based reader (Powerwave HT, Biotek) at $37^{\circ} \mathrm{C}$.

\section{NAD ${ }^{+}$assay}

Cellular $\mathrm{NAD}^{+}$content was determined using NAD/NADH Quantification Kit (Sigma) according to the manufacturer's protocol. The amount of NAD ${ }^{+}$ present in the samples was quantified in a colorimetric assay, measured at
$450 \mathrm{~nm}$ using a microplate reader. The amount of $\mathrm{NAD}^{+}$was normalized to protein content, quantified using the PierceTM BCA Protein Assay.

\section{PARP1 and PAR western blotting}

HPDE cells were seeded in 12 well/plates at the confluence of $2 \times 10^{5}$ cells/ well and after $24 \mathrm{~h}$ they were pretreated with olaparib $1 \mu \mathrm{M}$ to $100 \mu \mathrm{M}$ and then treated with $\mathrm{H}_{2} \mathrm{O}_{2}(300 \mu \mathrm{M})$ for $1 \mathrm{~h}$. The cells were collected and the total cell extracts were prepared homogenizing the cells in NP-40 lysis buffer $(50 \mathrm{mM}$ Tris- $\mathrm{HCl} \mathrm{pH} 8.0,150 \mathrm{mM} \mathrm{NaCl}, 1 \%$ Nonidet P-40) in the presence of protease inhibitor (Roche) followed by clean-up centrifugation at $20,000 \times \mathrm{g}$ for $10 \mathrm{~min}$. Proteins were separated by SDS-PAGE and transferred to nitrocellulose membrane (Bio-Rad, Hercules, Calif). The membrane was blocked in Thermo Scientific Starting Block Blocking Buffer (Thermo Fisher Scientific, Waltham, Mass) followed by exposure to primary antibodies anti-PARP-1(1:1,000; 46D11 Cell Signaling) and poly(ADP-ribose) (PAR, the enzymatic product of the PARP enzyme and a marker of PARP's catalytic activation) $(1: 1,000$; 4336-BPC-100 Trevigen) overnight at $4{ }^{\circ} \mathrm{C}$. The anti-rabbit IgG conjugated to horseradish peroxidase (1:2,000; Cell Signaling) was used as secondary antibody. After incubating with secondary antibody for $1 \mathrm{~h}$ at room temperature, the membrane was developed with SuperSignal West Pico Chemiluminescent Substrate (Pierce) in a GeneBox Detection System (Syngene).

\section{Quantification of DNA integrity}

Measurement of mitochondrial and nuclear DNA integrity was conducted using gene-specific semiquantitative PCRs as described (29). Briefly, HPDE cells were seeded in 12-well plates (200,000 cell/well). Total DNA was isolated using DNasey Blood and Tissue Kit (QIAGEN). Integrity of the mtDNA was assessed using two set pairs of primers with amplicon of $211 \mathrm{bp}$ and $8.9 \mathrm{~kb}$ (short amplicon was used as a normalization factor of mtDNA copies). Integrity of the nuclear DNA was assessed using $10 \mathrm{~kb}$ amplicon. Taq DNA Polymerase and LongAmp Taq DNA polymerase (both from NewEngland BioLabs) were used for amplification of short and long DNA targets, respectively. DNA integrity in untreated (control) cells was set as $100 \%$.

\section{Immunohistochemical detection of PARylation in human clinical samples obtained from pancreatitis patients}

Pancreas tissue arrays (BBS14011 and PA2081) containing normal pancreatic tissue from autopsy and pancreatic tissues from patients with acute or chronic pancreatic inflammation were purchased from US Biomax Inc (Derwood, MD 20855). Immunohistochemical staining for PAR (the product of PARP) was conducted in deparaffinized tissue sections using a PAR antibody (Tulip mouse monoclonal, anti-human 1:10). $\mathrm{n}=3$ normal controls, $\mathrm{n}=3$ acute pancreatitis sections, and $\mathrm{n}=6$ chronic pancreatitis sections (all from different subjects/patients) were analyzed.

\section{Statistical analysis}

All values described in the text and figures are expressed as means $\pm \mathrm{SEM}$ for $n$ observations. The one-way analysis of variance (ANOVA) is used to determine whether there are any statistically significant differences between the means of the three groups (control, cerulean, and olaparib+cerulein in the in vivo experiments or control, oxidative stress, and olaparib+oxidative stress in the in vitro experiments). When the one-way ANOVA returned a statistically significant result, we concluded that are at least two group means that are statistically significantly different from each other. At this point, Tukey posthoc test was used to determine whether the insult (cerulein in vivo or oxidative stress in vitro) has an effect on a given parameter compared with normal control values (animals not subjected to cerulein or cells not subjected to $\mathrm{H}_{2} \mathrm{O}_{2}$ ) and to detect if olaparib affected the response in the groups that were subjected to the insult (cerulein in vivo or oxidative stress in vitro), compared with the groups that were subjected to the same insults in the absence of olaparib. Prism version 5 for Windows (Graph Pad Software) was used. $P<0.05$ was considered statistically significant.

\section{RESULTS}

\section{Olaparib exerts organ protective and anti-inflammatory effects in adult male mice subjected to cerulein-induced pancreatitis}

In adult male mice subjected to cerulein-induced pancreatitis, olaparib (3 mg/kg i.p.) improved several parameters of pancreatic dysfunction (Figs. 1-3). For instance, the 

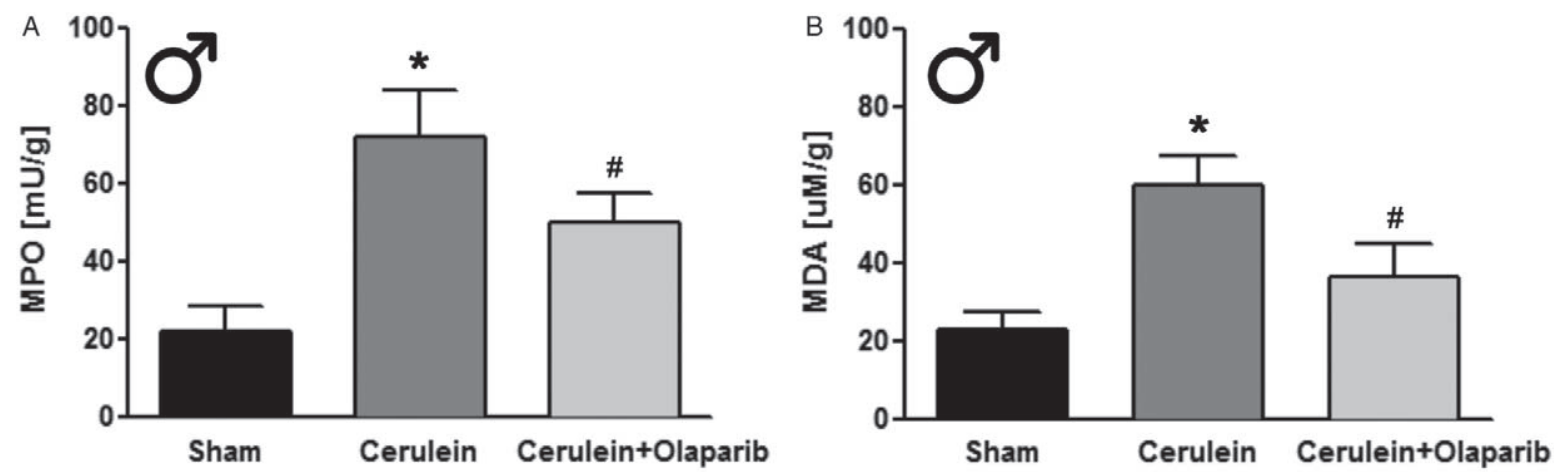

FIG. 1. Effect of olaparib on pancreatic MPO and MDA levels in male Balb/c mice subjected to cerulein-induced pancreatitis. (A) Pancreatic MPO levels (expressed as milliunits [mU]/gram tissue) and (B) pancreatic MDA levels (expressed as $\mu \mathrm{M} / \mathrm{g}$ tissue) are shown in sham mice (not subjected to cerulein) ("Sham"), in vehicle-treated mice subjected to cerulein at $6 \mathrm{~h}$ ("Cerulein") and in mice subjected to cerulein in the presence of olaparib ( $2 \mathrm{mg} / \mathrm{kg} \times 3 \mathrm{mg} / \mathrm{kg})(C e r u l e i n+O \mathrm{laparib})$. Data are shown as mean \pm SEM of 10 animals for each group; ${ }^{*} P<0.05$ shows significant increase in MPO or MDA in response to cerulein, compared with the sham group; \#P<0.05 shows significant protective effect of olaparib in cerulein-pancreatitis mice compared with vehicle-treated cerulein-pancreatitis mice.
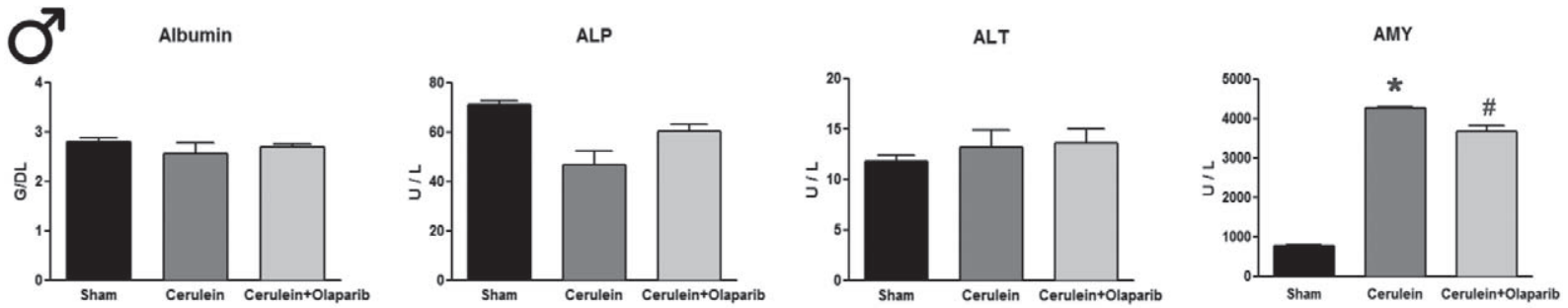

TBIL
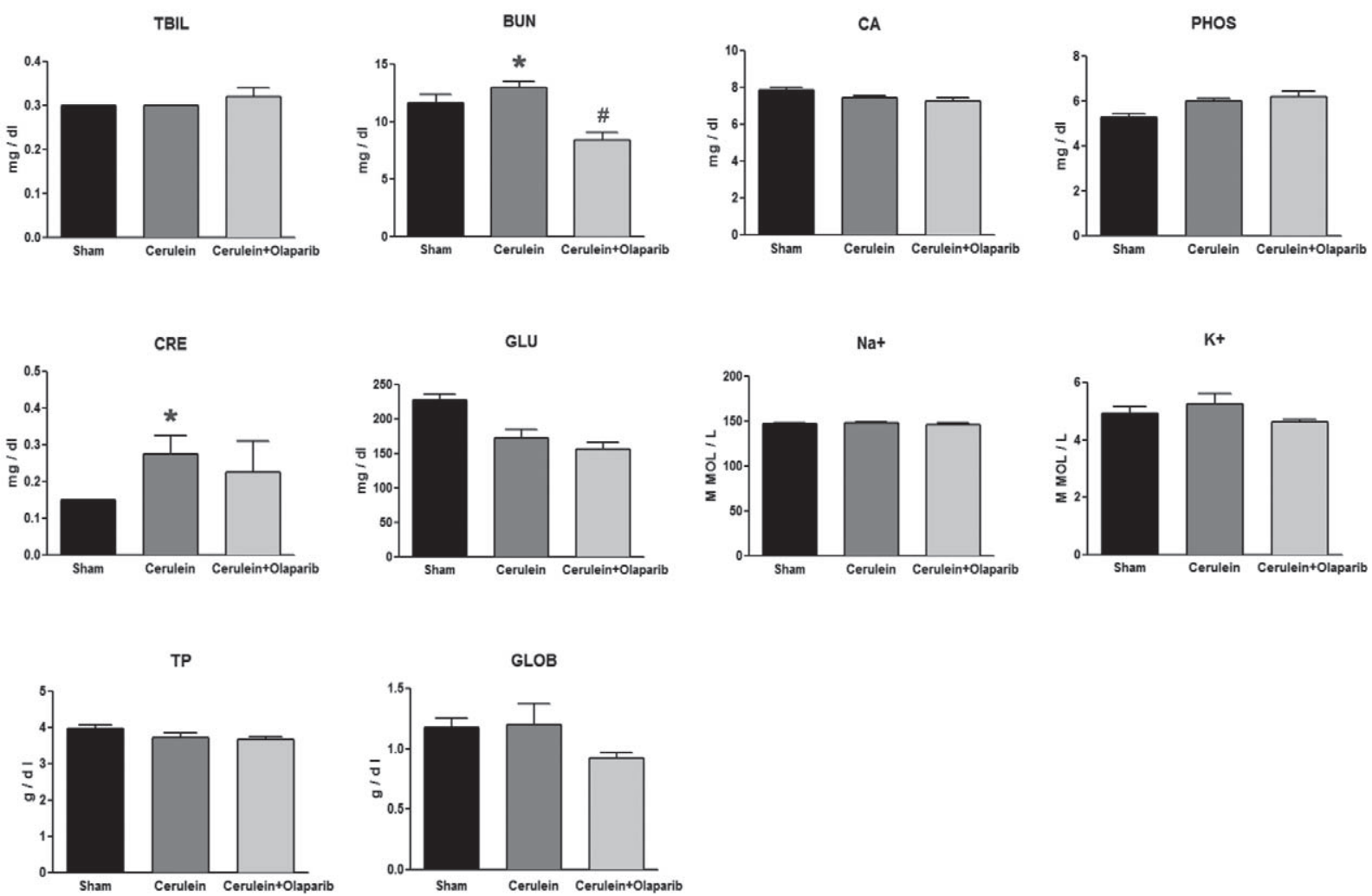

FIG. 2. Effect of olaparib on selected parameters of organ injury in male Balb/c mice subjected to cerulein-induced pancreatitis. Various physiological and organ injury marker levels: alkaline phosphatase (ALP), alanine aminotransferase (ALT), amylase (AMY), total bilirubin (TBIL), plasma blood urea nitrogen (BUN), plasma calcium $\left(\mathrm{CA}^{++}\right)$, plasma phosphate (PHOS), plasma creatinine (CRE), plasma glucose (GLU), plasma sodium $\left(\mathrm{Na}^{+}\right)$, plasma potassium $\left(\mathrm{K}^{+}\right)$, total protein (TP), and plasma globulin (GLOB) measured by Vetscan analysis, are shown in sham mice (not subjected to cerulein) ("Sham"), in vehicle-treated mice subjected to cerulein at $6 \mathrm{~h}$ ("Cerulein") and in mice subjected to cerulein in the presence of olaparib ( $2 \mathrm{mg} / \mathrm{kg} \times 3 \mathrm{mg} / \mathrm{kg}$ ) (Cerulein+Olaparib). Data are shown as mean \pm SEM of 10 animals for each group; ${ }^{*} P<0.05$ shows significant increase in the respective parameter in response to cerulein, compared with the sham group; $\# P<0.05$ shows significant protective effect of olaparib in cerulein-pancreatitis mice compared with vehicle-treated cerulein-pancreatitis mice. 


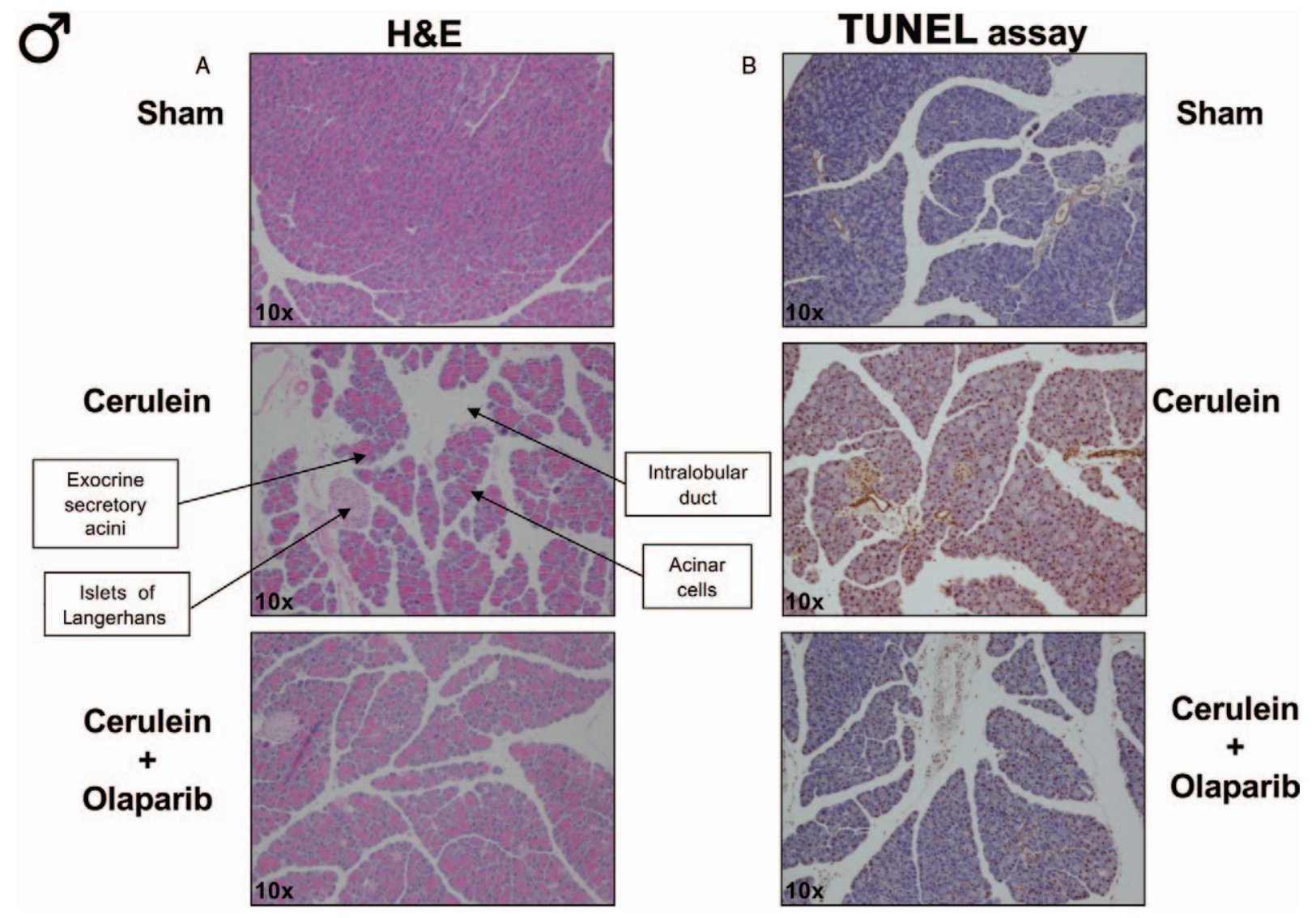

FIG. 3. Effect of olaparib on histological alterations injury in the pancreas of male Balb/c mice subjected to cerulein-induced pancreatitis. (A) Representative histological pictures and (B) TUNEL staining are shown in sham mice (not subjected to CLP) ("Sham"), in vehicle-treated mice subjected to cerulein at $6 \mathrm{~h}$ ("Cerulein") and in mice subjected to cerulein in the presence of olaparib ( $2 \mathrm{mg} / \mathrm{kg} \times 3 \mathrm{mg} / \mathrm{kg})(\mathrm{Cerulein}+\mathrm{Olaparib})$. Pictures are selected from $\mathrm{n}=5$ animals for each group. Figure is available in color online.

cerulein-induced increases in pancreatic MPO and MDA content (indicative of neutrophil infiltration and intraorgan oxidative stress, respectively) were attenuated by olaparib (Fig. 1). In addition, the cerulein-induced increases in the plasma marker of pancreatic injury (amylase) and renal dysfunction (BUN) were also attenuated by olaparib treatment (Fig. 2). The histopathological pictures of the pancreas showed evidence of cellular damage, as well as DNA damage/apoptosis (assessed by the TUNEL assay); these alterations were also improved by olaparib treatment (Fig. 3). Representative images are shown in Figure 3; histopathological images from five animals per group are shown in Supplemental Fig. 1, Supplemental Digital Content 1, http://links.lww.com/SHK/A909.

Olaparib attenuated the cerulein-induced increases in the levels of several circulating mediators in the plasma (e.g., TNF $\alpha$, IL-1 $\beta$, IL-2, IL-4, IL-6, IL-12, IP-10, KC), while plasma levels of other circulating mediators (e.g., KC, IL-10, RANTES, VEGF) were unaffected (Fig. 4).

\section{The beneficial effects of olaparib are maintained in female mice subjected to pancreatitis}

As discussed in our position paper (20), in many experimental models, the beneficial effects of pharmacological PARP inhibition or genetic PARP deficiency are gender-dependent, with the effects diminishing or nonexistent in female animals.
Importantly, this gender difference is very prominent in endotoxin-induced systemic inflammation models (30) and in cecal ligation and puncture induced sepsis models (27). In the current pancreatitis model, however, the therapeutic effect of olaparib remained significant in female mice (Figs. 5-8). Olaparib attenuated the cerulein-induced increases in pancreatic MPO levels in female mice, although to a lesser degree than in males (Fig. 5); however, it failed to significantly affect pancreatic MDA levels. In addition, the cerulein-induced increases in plasma amylase, BUN, and creatinine were also attenuated by olaparib treatment (Fig. 6). In contrast to the male mice, in female mice we have detected a significant cerulein-induced increase in circulating ALT levels (indicative of hepatic dysfunction); however, this was unaffected by olaparib (Fig. 6). There was also evidence of cerulein-induced hyperglycemia in female mice (perhaps indicative of pancreatic beta cell damage), and this was mitigated by olaparib (Fig. 6). The histopathological pictures of the pancreas showed evidence of cellular damage, which was improved by olaparib treatment (Fig. 7).

\section{Olaparib exerts cytoprotective effects in HPDE cells subjected to oxidative stress in vitro, without adversely affecting DNA integrity}

In HPDE cells subjected to oxidative stress, olaparib inhibited PARylation (as measured by the quantification of 

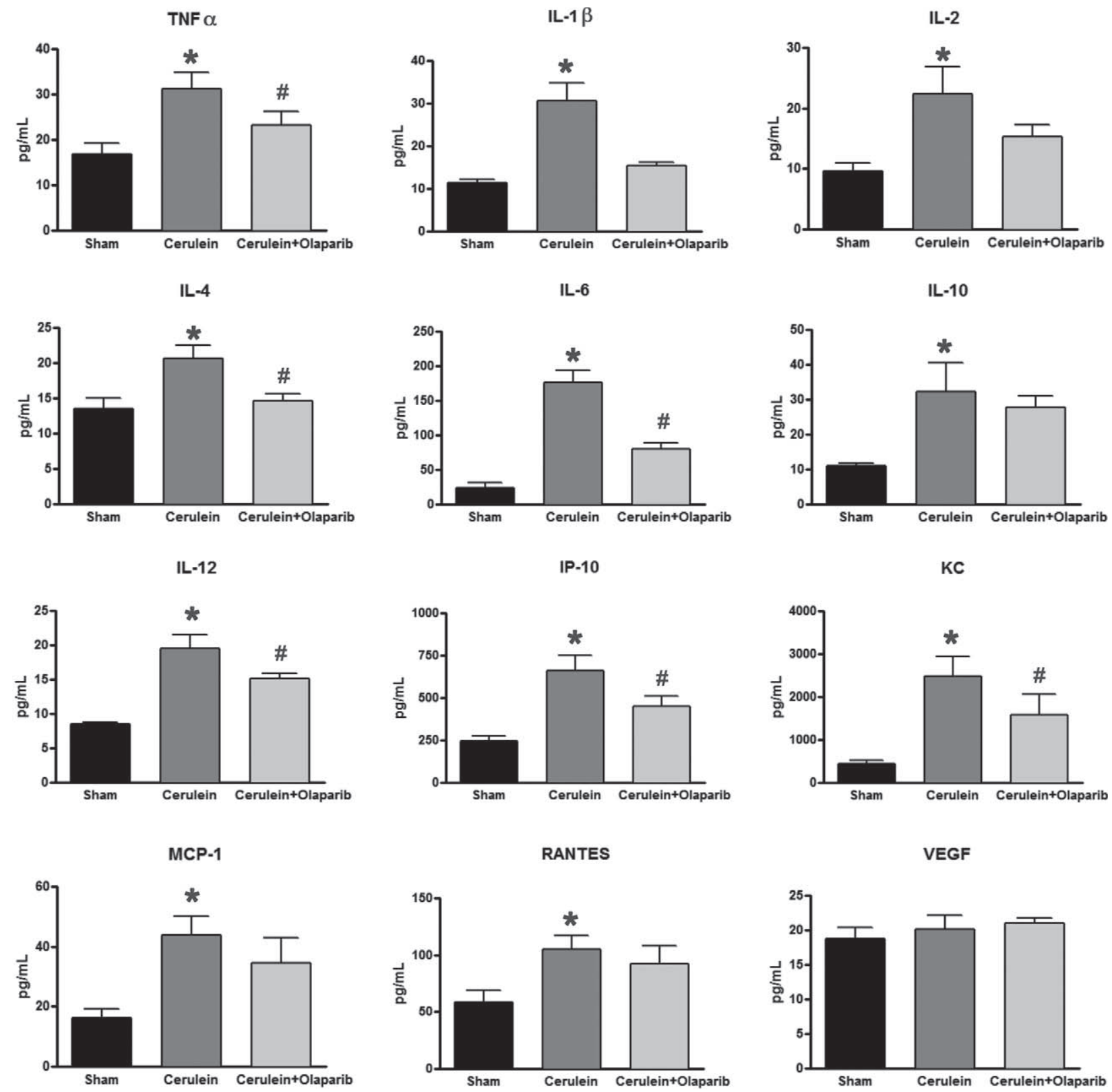

FIG. 4. Effect of olaparib on the levels of various circulating mediators (cytokines, chemokines, growth factors) in male Balb/c mice subjected to cerulein-induced pancreatitis. Values are shown in sham mice (not subjected to CLP) ("Sham"), in vehicle-treated mice subjected to cerulein at $6 \mathrm{~h}$ ("Cerulein") and in mice subjected to cerulein in the presence of olaparib $(2 \mathrm{mg} / \mathrm{kg} \times 3 \mathrm{mg} / \mathrm{kg})$ (Cerulein+Olaparib). ${ }^{*} P<0.05$ shows significant increase in the respective parameter in response to cerulein, compared with the sham group; $\# P<0.05$ shows significant protective effect of olaparib in cerulein-pancreatitis mice compared with vehicle-treated cerulein-pancreatitis mice.

poly(ADP-ribose) [PAR], the product of the enzyme) already at the lowest concentration $(1 \mu \mathrm{M})$ used, confirming the wellestablished (31) potent inhibitory effect of olaparib on PARP1 catalytic activity in this cell line (Fig. 8). PARP1 enzyme levels were downregulated by the oxidative stress challenge; this downregulation was also partially attenuated by the lower concentrations $(1 \mu \mathrm{M}-3 \mu \mathrm{M})$ of olaparib (Fig. 8). In line with prior findings demonstrating that PARP inhibition prevents the cellular depletion of its substrate, $\mathrm{NAD}^{+}(4,32)$, olaparib also protected against the $\mathrm{H}_{2} \mathrm{O}_{2}$-induced loss of cellular $\mathrm{NAD}^{+}$ levels, with the effects already near-maximal at its lowest concentration tested (1 $\mu \mathrm{M})$ (Fig. 9).
Consistent with prior findings demonstrating the protective effect of PARP inhibitors in cells exposed to various oxidants $(4,32,33)$ olaparib $(1 \mu \mathrm{M})$ protected against the $\mathrm{H}_{2} \mathrm{O}_{2}$-induced loss of cell viability, indicated by continued MTT reduction in the presence of olaparib treatment (Fig. 10). Although the $\mathrm{H}_{2} \mathrm{O}_{2}$-induced inhibition of MTT reductive capacity, as well as the marked drop in $\mathrm{NAD}^{+}$levels predicted the development of significant cell dysfunction, this was not associated with any apparent necrosis, as LDH levels in the cell culture supernatant did not increase after $\mathrm{H}_{2} \mathrm{O}_{2}$ challenge (Fig. 10).

In a broad concentration range $(1 \mu \mathrm{M}-100 \mu \mathrm{M})$, olaparib did not have any adverse effects on nuclear or mitochondrial DNA 
$Q^{A}$

MPO

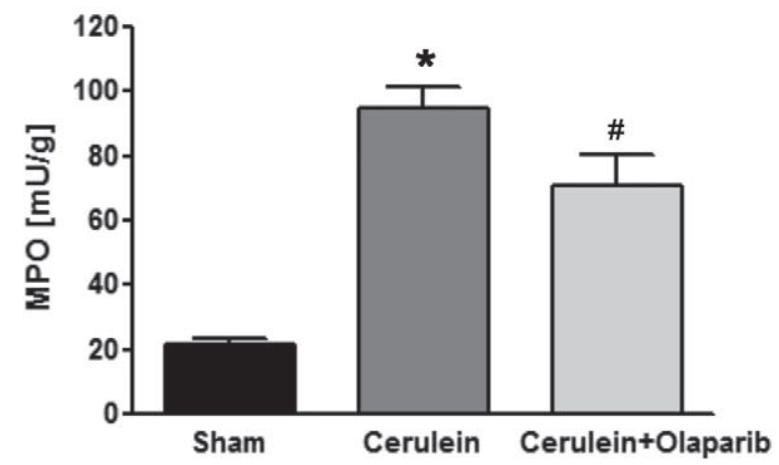

B

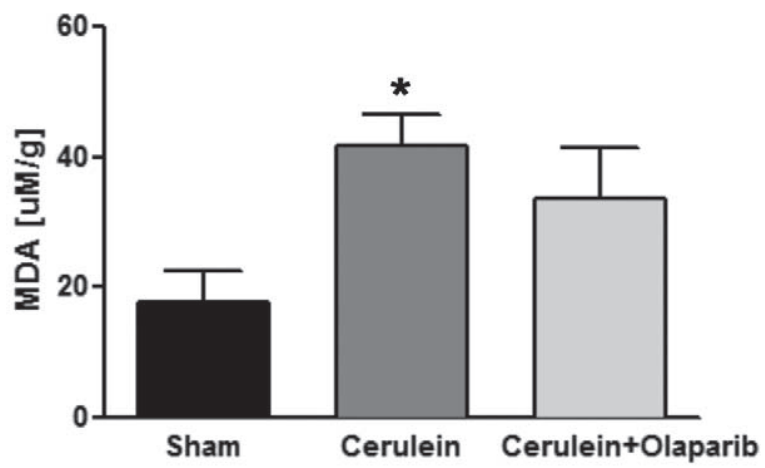

FIG. 5. Effect of olaparib on pancreatic MPO and MDA levels in female Balb/c mice subjected to cerulein-induced pancreatitis. (A) Pancreatic MPO levels (expressed as milliunits [mU]/g tissue) and (B) pancreatic MDA levels (expressed as $\mu \mathrm{M} / \mathrm{gram}$ tissue) are shown in sham mice (not subjected to cerulein) ("Sham"), in vehicle-treated mice subjected to cerulein at $6 \mathrm{~h}$ ("Cerulein") and in mice subjected to cerulein in the presence of olaparib (2 mg/kg $\times 3 \mathrm{mg} / \mathrm{kg})$ (Cerulein+Olaparib). Data are shown as mean \pm SEM of 10 animals for each group; ${ }^{*} P<0.05$ shows significant increase in MPO or MDA in response to cerulein, compared with the sham group; $\# P<0.05$ shows significant protective effect of olaparib against the increase in MPO in cerulein-pancreatitis mice compared with vehicle-treated cerulein-pancreatitis mice.

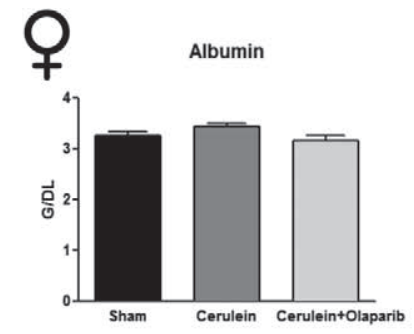

TBIL

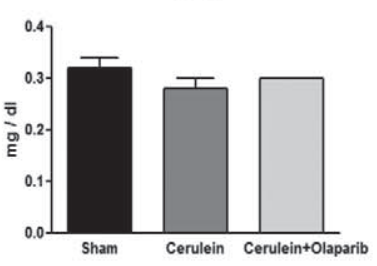

CRE

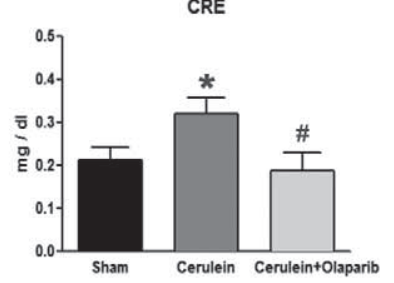

TP

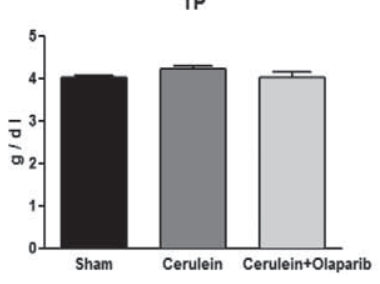

ALP

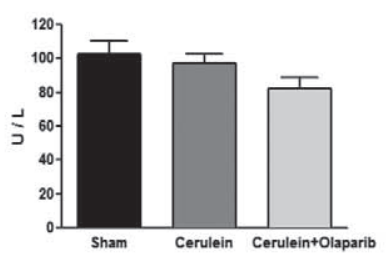

BUN

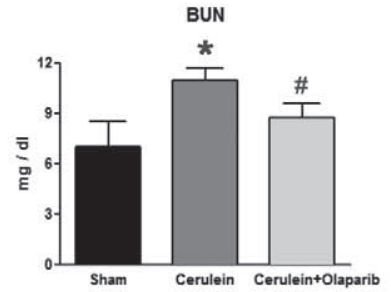

GLU

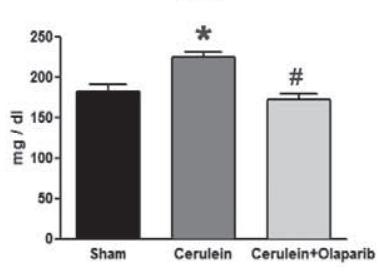

GLOB

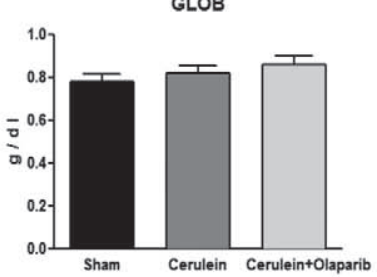

ALT

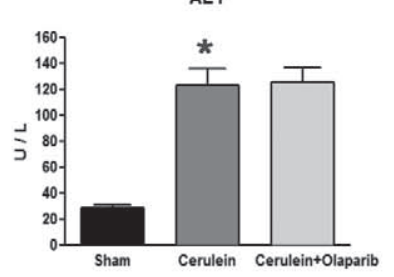

CA

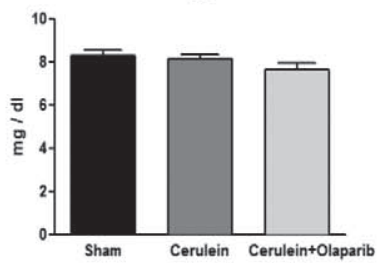

$\mathrm{Na}+$

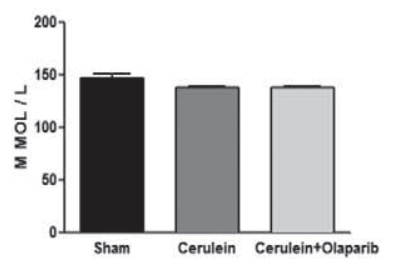

AMY

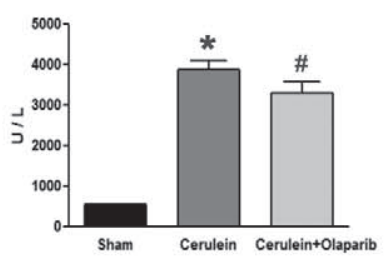

PHOS

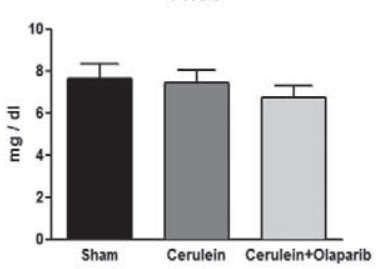

K+

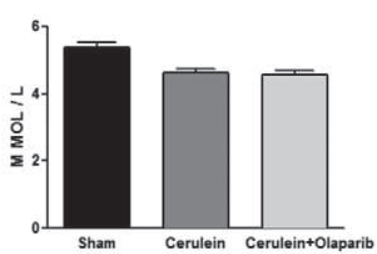

FIG. 6. Effect of olaparib on selected parameters of organ injury in female Balb/c mice subjected to cerulein-induced pancreatitis. Various physiological and organ injury marker levels: alkaline phosphatase (ALP), alanine aminotransferase (ALT), amylase (AMY), total bilirubin (TBIL), plasma blood urea nitrogen (BUN), plasma calcium $\left(\mathrm{CA}^{++}\right)$, plasma phosphate (PHOS), plasma creatinine (CRE), plasma glucose (GLU), plasma sodium (Na ${ }^{+}$), plasma potassium ( $\left.\mathrm{K}^{+}\right)$, total protein (TP), and plasma globulin (GLOB) measured by Vetscan analysis, are shown in sham mice (not subjected to cerulein) ("Sham"), in vehicle-treated mice subjected to cerulein at $6 \mathrm{~h}$ ("Cerulein") and in mice subjected to cerulein in the presence of olaparib $(2 \mathrm{mg} / \mathrm{kg} \times 3 \mathrm{mg} / \mathrm{kg})(\mathrm{Cerulein}+\mathrm{Olaparib})$. Data are shown as mean \pm SEM of 10 animals for each group; ${ }^{*} P<0.05$ shows significant increase in the respective parameter in response to cerulein, compared with the sham group; $\# P<0.05$ shows significant protective effect of olaparib in cerulein-pancreatitis mice compared with vehicle-treated cerulein-pancreatitis mice. 


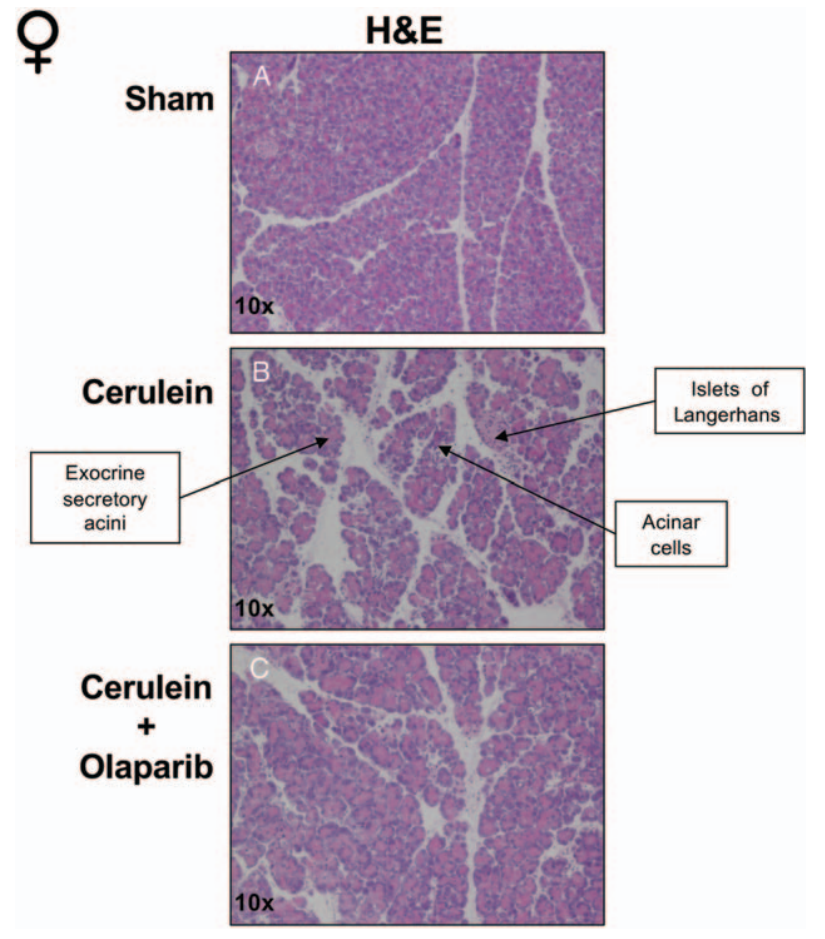

FIG. 7. Effect of olaparib on histological alterations injury in the pancreas of female Balb/c mice subjected to cerulein-induced pancreatitis. Representative histological pictures are shown in sham mice (not subjected to CLP) ("Sham"), in vehicle-treated mice subjected to cerulein at $6 \mathrm{~h}$ ("Cerulein") and in mice subjected to cerulein in the presence of olaparib (2 mg/kg $\times 3 \mathrm{mg} / \mathrm{kg})$ (Cerulein+Olaparib). Pictures are selected from $\mathrm{n}=5$ animals for each group.

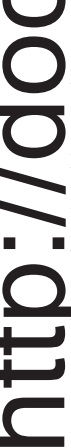

integrity in control cells (i.e., cells not subjected to oxidative stress) (Fig. 11A) but reduced the degree of oxidative stressinduced mitochondrial DNA damage at $1 \mathrm{~h}$ postoxidant challenge (Fig. 11B). We attribute this finding to effects on the mitochondrial isoform of PARP, which has a qualitatively different role in the regulation of mitochondrial DNA repair than its nuclear counterpart $(34,35)$. While mitochondrial DNA

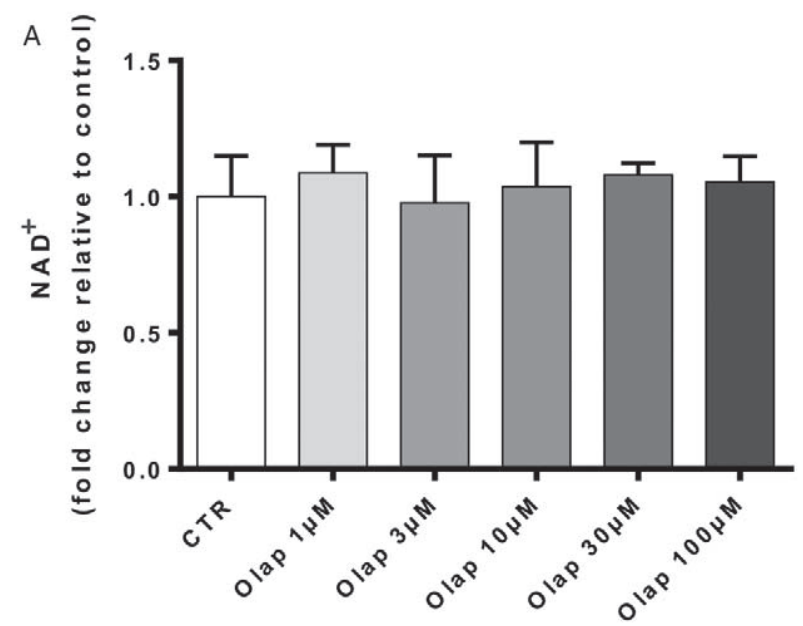

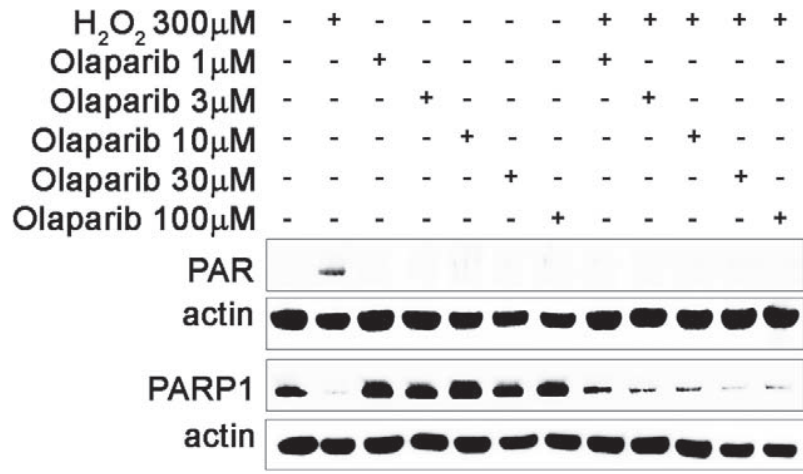

FIG. 8. Effect of olaparib on PARP and PAR levels in HPDE cells subjected to hydrogen peroxide-induced oxidative stress. Western blotting for PAR the enzymatic product of PARP activation and its actin loading control (top lanes) and PARP1 and its actin loading control (bottom lanes) in HPDE cells treated with olaparib $(1 \mu \mathrm{M}, 3 \mu \mathrm{M}, 10 \mu \mathrm{M}, 30 \mu \mathrm{M}$, or $100 \mu \mathrm{M})$ in control and in $300 \mu \mathrm{M} \mathrm{H}_{2} \mathrm{O}_{2}$ (" $\mathrm{H}$ ") challenged cells at $1 \mathrm{~h}$. Note the increase in PAR (indicative of PARP activation) in response to oxidative stress, and the full inhibition of this response at all olaparib concentrations tested. The expression of PARP1 was reduced by oxidative stress, and this was partially prevented by olaparib at $1 \mu \mathrm{M}$ to $10 \mu \mathrm{M}$. Western blots shown are representative of experiments performed on three different experimental days.

integrity partially recovered by $24 \mathrm{~h}$ post- $\mathrm{H}_{2} \mathrm{O}_{2}$ challenge, nuclear DNA damage became more extensive by $24 \mathrm{~h}$. The nuclear DNA damage at $24 \mathrm{~h}$ was slightly exacerbated by the two highest concentrations of olaparib tested $(30 \mu \mathrm{M}$ and $100 \mu \mathrm{M}$ ); however, the lower concentrations of olaparib did not have any adverse effects on DNA integrity at any of the time points and any of the experimental conditions tested. The latter findings are consistent with the role of PARP in the maintenance of nuclear DNA integrity, as well as with the idea that inhibition of DNA repair requires high concentrations of the PARP inhibitor (e.g., $30 \mu \mathrm{M}-100 \mu \mathrm{M}$ in our study), while the cytoprotective and $\mathrm{NAD}^{+}$-preserving effects of the same inhibitor manifest at lower concentrations (e.g., $1 \mu \mathrm{M}$ in our study).

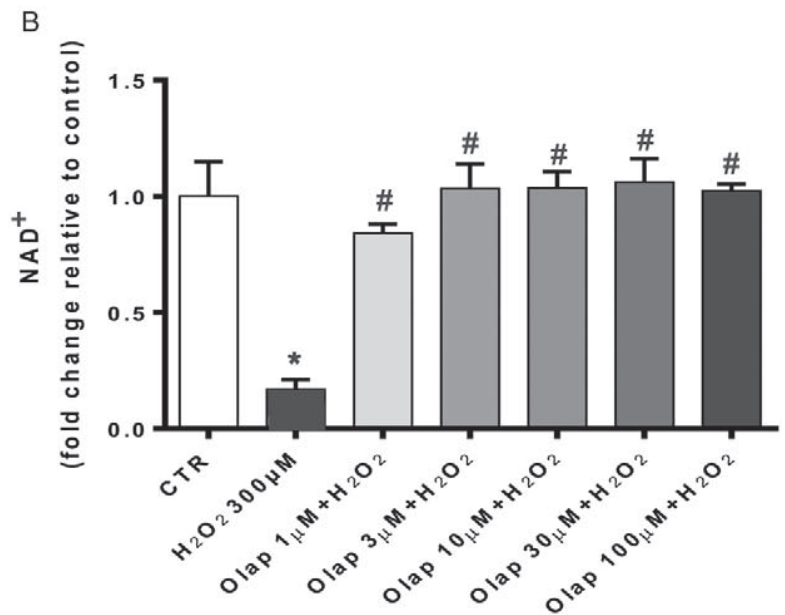

FIG. 9. Effect of olaparib on PARP activation and cellular NAD levels in HPDE cells subjected to $\mathrm{H}_{2} \mathrm{O}_{2}$-induced oxidative stress in vitro. Cells were treated with olaparib $(1 \mu \mathrm{M}, 3 \mu \mathrm{M}, 10 \mu \mathrm{M}, 30 \mu \mathrm{M}$, or $100 \mu \mathrm{M})$ and then subjected to oxidative stress $\left(\mathrm{H}_{2} \mathrm{O}_{2}\right)$ or its vehicle for $1 \mathrm{~h}$. ${ }^{*} P<0.05$ shows significant decrease in $\mathrm{NAD}^{+}$levels in response to $\mathrm{H}_{2} \mathrm{O}_{2}$, compared with control cells; ${ }^{\#} P<0.05$ shows significant protective effect of olaparib in $\mathrm{H}_{2} \mathrm{O}_{2}$ challenged cells compared with vehicle-treated $\mathrm{H}_{2} \mathrm{O}_{2}$ challenged cells. Data are shown as mean \pm SEM of $n=3$ determinations. 

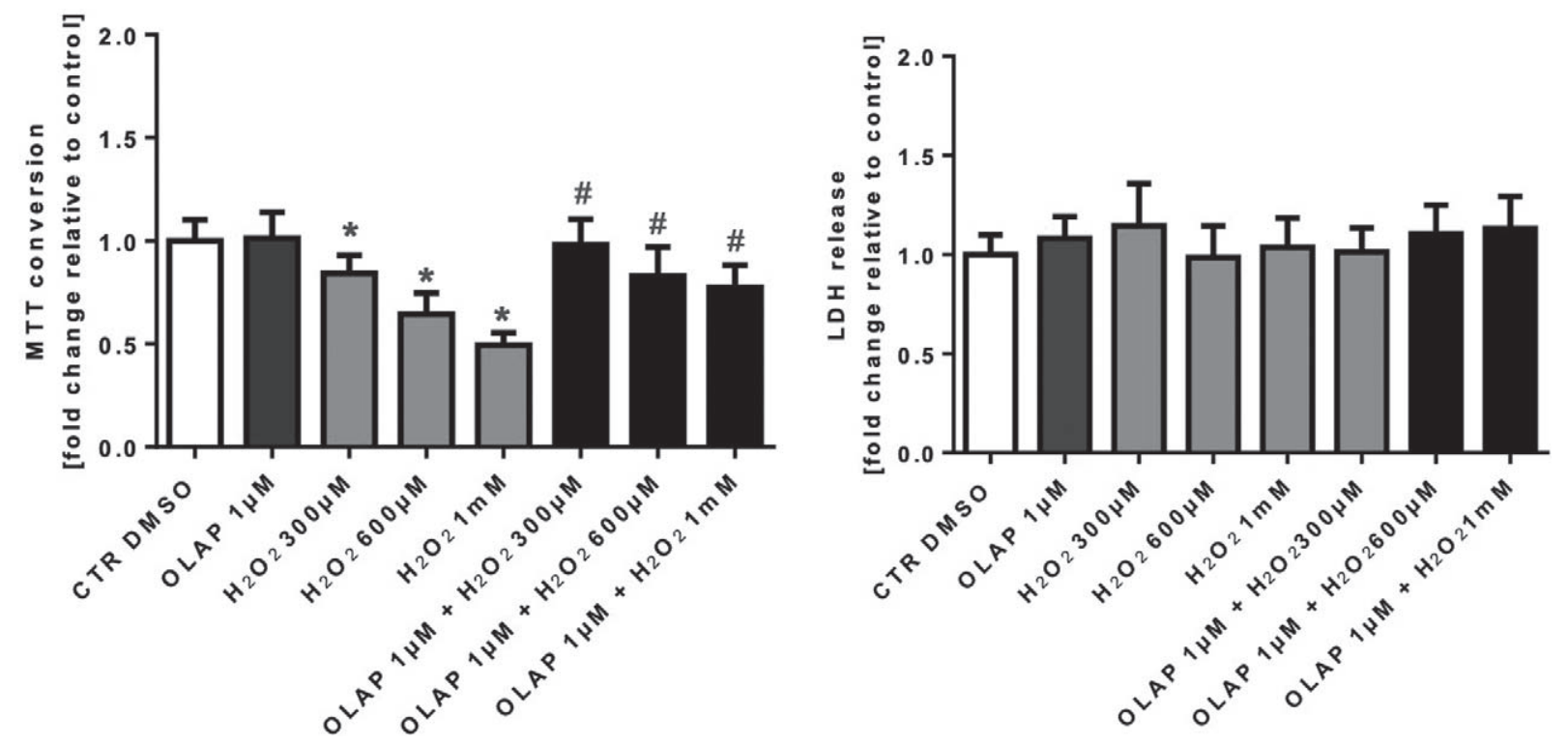

FIG. 10. Effect of olaparib on cellular viability in HPDE cells subjected to $\mathrm{H}_{2} \mathrm{O}_{2}$-induced oxidative stress in vitro. A, Effect of olaparib on cellular MTT conversion in cells subjected to oxidative stress $\left(300 \mu \mathrm{M}, 600 \mu \mathrm{M}\right.$, or $\left.1 \mathrm{mM} \mathrm{H}_{2} \mathrm{O}_{2}\right)$ in the presence of olaparib vehicle or $1 \mu \mathrm{M}$ olaparib. Data are shown as mean \pm SEM of $n=3$ determinations. ${ }^{*} P<0.05$ shows significant decrease in MTT conversion in response to $\mathrm{H}_{2} \mathrm{O}_{2}$, compared with control cells; \#P<0.05 shows significant protective effect of olaparib in $\mathrm{H}_{2} \mathrm{O}_{2}$ challenged cells compared with vehicle-treated $\mathrm{H}_{2} \mathrm{O}_{2}$ challenged cells at the same $\mathrm{H}_{2} \mathrm{O}_{2}$ concentration. $\mathrm{B}$, Effect of

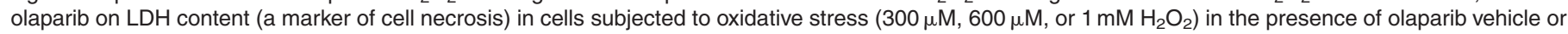
$1 \mu \mathrm{M}$ olaparib. Data are shown as mean \pm SEM of $n=3$ determinations. Data are shown as mean \pm SEM of $n=3$ determinations.

\section{Immunohistochemical detection of PARylation in human clinical samples obtained from pancreatitis patients}

In pancreas histological sections of patients who died of acute or chronic pancreatitis, accumulation of PAR (the product of PARP) was demonstrated, while in healthy control pancreatic tissues no PAR immunostaining was detectable (Fig. 12). The PAR staining was primarily nuclear, but also perinuclear and cytosolic; it was apparent both in acute and chronic pancreatitis sections.

\section{DISCUSSION}

We conclude that in mice subjected to cerulein-induced pancreatitis, the PARP clinically approved PARP inhibitor olaparib improves pancreatic function, beneficially modulates the systemic inflammatory response (reduction of the plasma level of various pro-inflammatory mediators, but no inhibition of the anti-inflammatory cytokine IL-10), and reduces the biochemical markers of renal injury. The protective effects of olaparib were evident at $3 \mathrm{mg} / \mathrm{kg}$, which is a relatively low dosage of the inhibitor, compared with the higher doses (typically $50 \mathrm{mg} / \mathrm{kg}-100 \mathrm{mg} / \mathrm{kg}$ ) used in the oncological context (34-41). The olaparib dose in the present study was selected based on prior studies using this PARP inhibitor in rodent models in various nononcological contexts including sepsis, stroke, and acute lung injury (22-27). There are a limited number of published pharmacokinetic studies with olaparib in rodents. A $100 \mathrm{mg} / \mathrm{kg}$ oral dosing of olaparib resulted in plasma

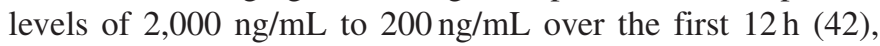
which corresponds to approximately $5 \mu \mathrm{M}$ to $0.5 \mu \mathrm{M}$ olaparib plasma concentration. Based on these data, we estimate that in the current study (with $3 \mathrm{mg} / \mathrm{kg}$ olaparib dosing, intraperitoneally, as opposed to orally), the achieved plasma concentrations of olaparib were likely in the high nanomolar range, perhaps up to $0.5 \mu \mathrm{M}$. (However, it should be noted that for PARP inhibitors it is the intracellular concentrations that are relevant and not the plasma levels; tissue levels can be in fact higher than plasma levels, especially at later time points- 12 to $24 \mathrm{~h}$ - after administration (42), but no published data exist specifically regarding pancreatic tissue olaparib levels).

The in vitro experiments, complementing the in vivo studies, established that olaparib also exerts protective effects against oxidant-induced cell injury - once again, at a low concentration of $1 \mu \mathrm{M}$-which, once again, is markedly lower than the concentrations of the PARP inhibitor used in cancer cells to exert cytotoxic effects and/or to enhance the cytotoxic action of various chemotherapeutic agents $(30 \mu \mathrm{M}-100 \mu \mathrm{M}$ or higher) (40-48). As discussed previously in our position paper (20), this difference between the protective/nononcological dose and concentration of olaparib versus the oncological dose and concentration of the same molecule is very important, because one can predict that the lower doses of olaparib that would be used in the context of therapeutic repurposing would be associated with a more advantageous safety and adverse effect profile than the adverse effect profile of the drug that is documented in cancer patients.

The selection of the cell line used in the present paper requires some qualification. The pancreas consists of many different cell types, and each of these cell types can be affected by the inflammatory processes. When attempting to model pancreatitis in vitro, some investigators use acinar cell lines, while others use ductal epithelial cells. The utilization of the single-cell line in our study is a clear limitation of the current study. Even though PARP is expressed in most 
A

Control

B

$\mathrm{H}_{2} \mathrm{O}_{2}$
$1 \mathrm{~h}$ post
treatment

C $\mathrm{H}_{2} \mathrm{O}_{2}$
$24 \mathrm{~h}$ post
treatment
Mitochondrial DNA integrity
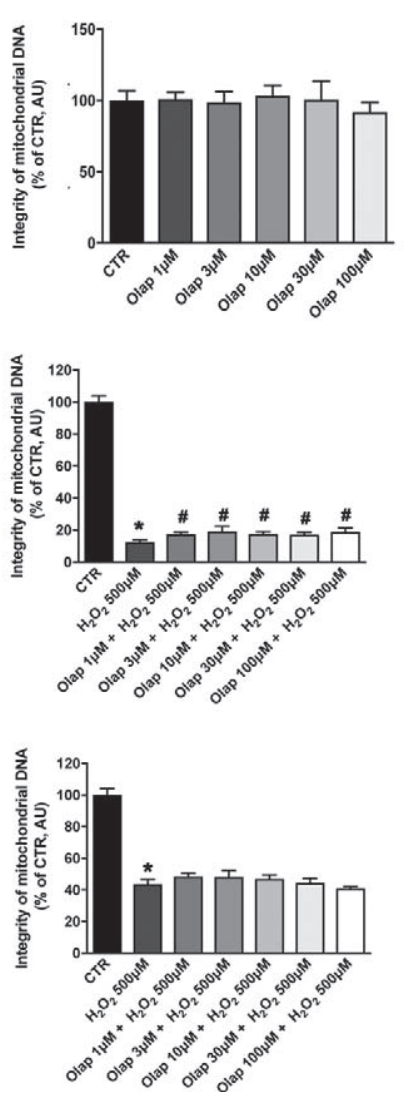

Nuclear DNA integrity
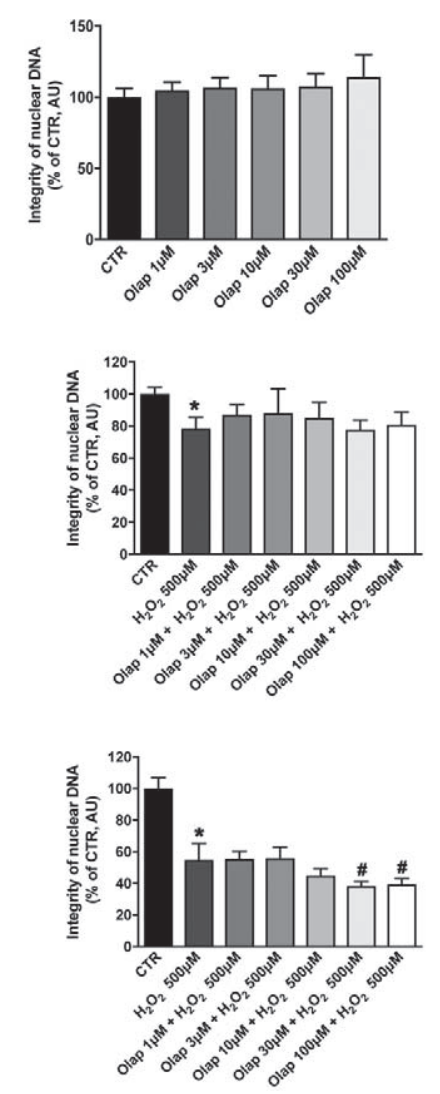

Mitochondrial DNA copies
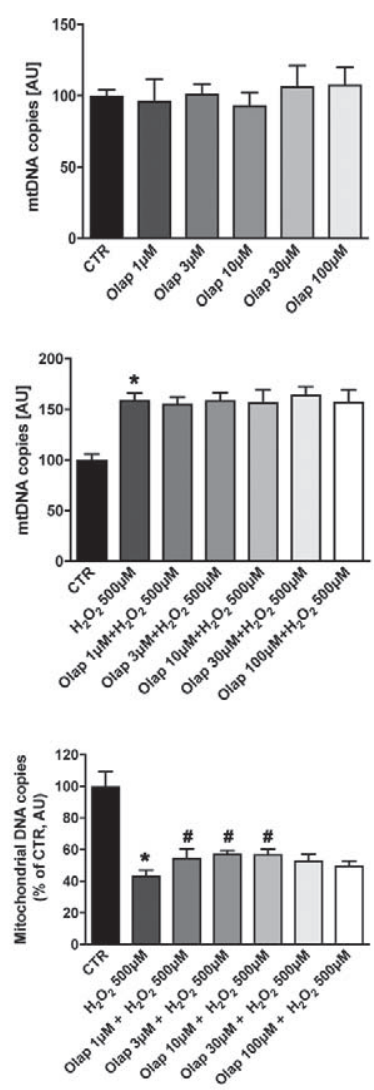

0

FIG. 11. Effect of olaparib on mitochondrial DNA integrity, mitochondrial DNA copy number, and nuclear DNA integrity in HPDE cells subjected to $\mathrm{H}_{2} \mathrm{O}_{2}$-induced oxidative stress in vitro. A, Mitochondrial DNA integrity, mitochondrial DNA copy number, and nuclear DNA integrity in control HPDE cells (without oxidative stress) subjected to vehicle or various concentrations of $(1 \mu \mathrm{M}, 3 \mu \mathrm{M}, 10 \mu \mathrm{M}, 30 \mu \mathrm{M}$, or $100 \mu \mathrm{M})$ olaparib for $24 \mathrm{~h}$ (data expressed as \% of control). B, Mitochondrial DNA integrity, mitochondrial DNA copy number, and nuclear DNA integrity in control HPDE cells (without oxidative stress) subjected to vehicle or various concentrations of olaparib $(1 \mu \mathrm{M}, 3 \mu \mathrm{M}, 10 \mu \mathrm{M}, 30 \mu \mathrm{M}$, or $100 \mu \mathrm{M})$, followed by treatment with $\mathrm{H}_{2} \mathrm{O}_{2}(500 \mu \mathrm{M})$ for $1 \mathrm{~h}$ (data expressed as \% of control). C, Mitochondrial DNA integrity, mitochondrial DNA copy number and nuclear DNA integrity in control HPDE cells (without oxidative stress) subjected to vehicle or various concentrations of olaparib $(1 \mu \mathrm{M}, 3 \mu \mathrm{M}, 10 \mu \mathrm{M}, 30 \mu \mathrm{M}$, or $100 \mu \mathrm{M})$, followed by treatment with $\mathrm{H}_{2} \mathrm{O}_{2}(500 \mu \mathrm{M})$ for $24 \mathrm{~h}$ (data expressed as \% of control). Results are shown as mean $\pm \mathrm{SEM}$ of $\mathrm{n}=3$ per condition. ${ }^{*} P<0.05$ shows a significant change in response to $\mathrm{H}_{2} \mathrm{O}_{2}$, compared with control cells; \#P<0.05 shows significant effect of olaparib in $\mathrm{H}_{2} \mathrm{O}_{2}$ challenged cells compared with vehicle-treated $\mathrm{H}_{2} \mathrm{O}_{2}$ challenged cells.

parenchymal cells (including acinar cells and epithelial cells, and vascular cells), and PARP-associated pathological processes have been previously reported in a wide variety of cell types during acute pancreatitis-including acinar cells (49), there may well be cell-type-specific differences in the relative contribution of PARP to the cell dysfunction or mediator production; this remains to be determined in followup experiments.

The PARP inhibitor's beneficial effects in various nononcological models of cell and organ injury and local and systemic inflammation are likely to have multiple mechanistic components. One aspect is likely related to direct cytoprotection (i.e., preservation of cellular $\mathrm{NAD}^{+}$and ATP levels); another aspect likely relates to the selective modulation of the expression and production of multiple pro-inflammatory mediators and circulating factors; these effects are likely to lead to secondary actions in vivo, e.g., the prevention of the infiltration of organs with activated mononuclear and polymorphonuclear cells, and maintenance of vascular integrity (20). We hypothesize that some combination of the above actions is responsible for the beneficial effects of olaparib in the current study.
Our findings are largely consistent with the results of prior studies focusing on PARP and pancreatitis that utilized PARP inhibitors of various structural classes. The first-generation PARP inhibitor 3-aminobenzamide was found to improve pancreatic histology and reduce bacterial translocation in a model of taurocholate-induced pancreatitis in rats; it also reduced serum amylase levels and attenuated renal dysfunction; moreover, serum concentrations of proinflammatory cytokines were also reduced by the inhibitor $(12,15,50)$. In another study, utilizing a structurally related compound, benzamide, once again, improved issue oxidative stress indices, better histological injury scores, reduced bacterial translocation, and improved survival were reported (14). One of the obvious problems with studies using 3-aminobenzamide or benzamide is the low potency of these compounds (for instance, benzamide was used at a dose of $100 \mathrm{mg} / \mathrm{kg}$ ); another is their low selectivity; as discussed elsewhere (51) they exert many non-PARP-related pharmacological actions. Moreover, they are not clinically approved and therefore they are not translationally relevant. Second-generation PARP inhibitors, for instance the phenanthridinone compound 

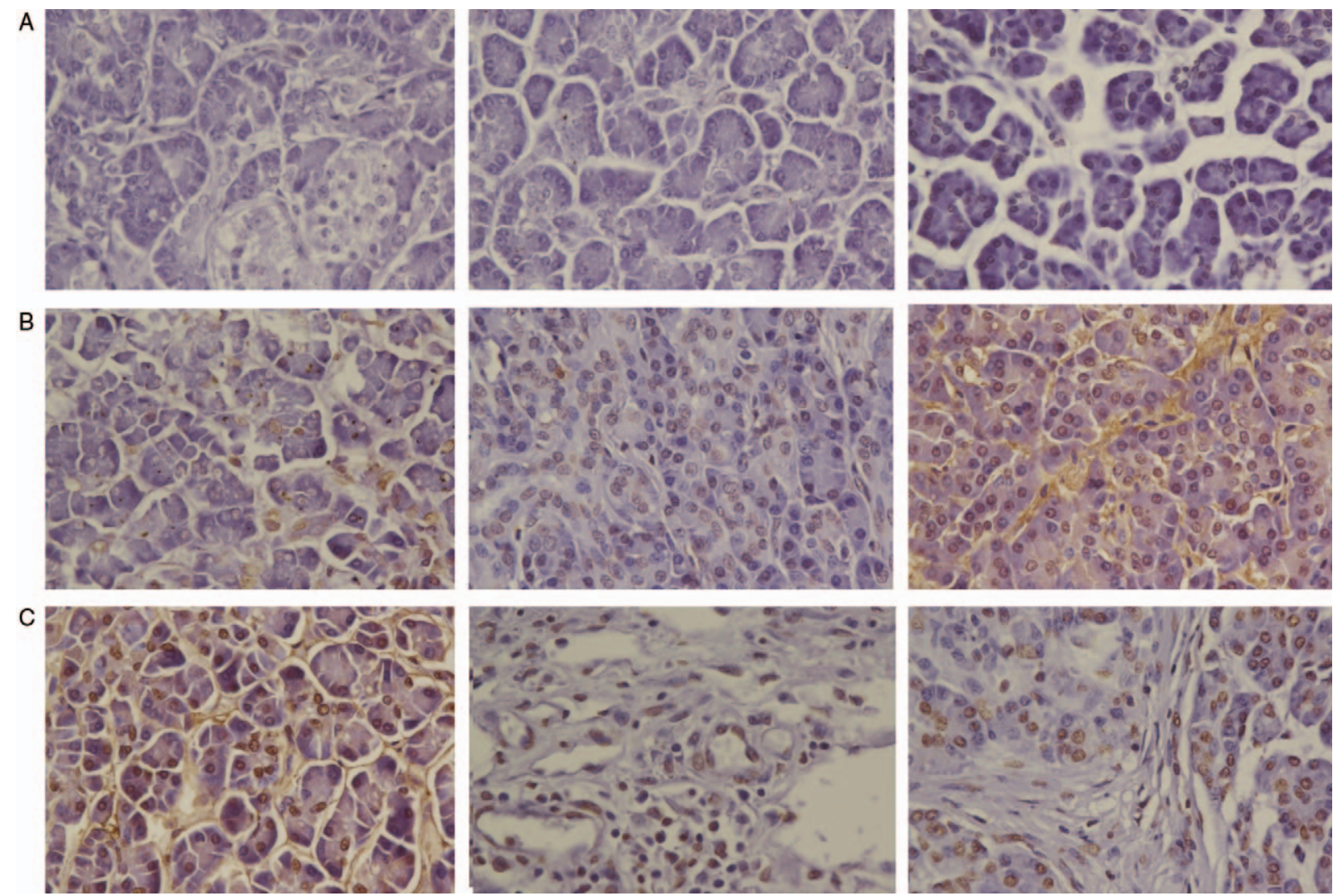

FIG. 12. Human pancreatitis is associated with PARP activation in the pancreatic tissue. A, PAR staining in normal control pancreatic tissue samples. B, PAR staining in pancreatic tissue samples obtained from patients with acute pancreatitis. C, PAR staining in pancreatic tissue samples obtained from patients with chronic pancreatitis. PAR accumulation in (B) and (C) is visible as a brown intracellular (nuclear, perinuclear, and cytoplasmic) staining. $\times 40$ magnification.

PJ34, are more potent, more selective to PARP (as opposed to other ribosylating enzymes) (51); PJ34, too, was reported to improve the outcome of acute pancreatitis in mice in a model of pancreatitis induced by choline/methionine-deficient/ethionine-supplemented (CMDE) diet: CMDE-induced increases in serum amylase, lipase, IL-1 $\beta$, IL-6, ALT, and AST levels, as well as the histological changes in pancreas, liver and lung were all improved by PJ34 therapy $(15 \mathrm{mg} / \mathrm{kg} /$ day) (11). Similar findings with PJ34 were also reported in a cerulein-induced pancreatitis model (13). The current report adds to this body of information and demonstrates that the clinically approved PARP inhibitor, olaparib, also exerts significant beneficial effects in an acute pancreatitis model. Interestingly, one of the prior studies, published in 2007 by Mota et al. (11), has also used a second-generation PARP inhibitor that was designated as KU0058684. This molecule was tested side-by-side with PJ34 (at the same dose of $15 \mathrm{mg}$ / $\mathrm{kg} / \mathrm{d}$ ) in the CMDE model and exhibited comparable efficacy. This molecule is now also a clinically approved anticancer drug similar to olaparib (its current designation is niraparib/ Zejula) (52). Thus, the body of evidence suggests that at least two of the currently clinically approved PARP inhibitors (niraparib and olaparib) may be potentially suitable for repurposing for the experimental therapy of acute pancreatitis.

There are several lines of preclinical studies that suggest that not all populations of animals subjected to various models of critical illness may benefit equally from PARP inhibition. For instance, in several models (ranging from stroke and endotoxemia and sepsis), in female mice the protective effect of PARP inhibition or PARP deficiency is diminished or non-significant; this difference may be related to a physiological inhibitory effect of estrogen on PARP activation (20). Surprisingly, in our current study, we found that olaparib was efficacious in our pancreatitis model both male and female animals; this is an important observation when considering future clinical trials focusing on therapeutic repurposing.

It has been known for several decades that PARP activity plays a role in the maintenance of DNA integrity, chiefly through the recruitment of various DNA repair enzymes and the assembly of nuclear and mitochondrial DNA repair complexes $(4,53,54)$. Inhibition of DNA repair is, in fact, the principal mode of action of olaparib's approved indication in the field of oncology, an effect that is more prominent when the cancer cells have certain mutations (e.g., mutations in the BRCA gene), or when cancer therapy is performed in combination with treatment with cytotoxic and/or genotoxic chemotherapeutics. Because of this important function of PARP, it is essential to separate the doses/concentrations of PARP inhibitors that are cytoprotective (and therefore relevant for potential therapeutic repurposing) and the doses/concentrations that are genotoxic or cytotoxic (or enhance anticancer therapy). Our experiments in the HPDE cell line have begun defining these concentration differences. Importantly, we have demonstrated 
that in these cells, $1 \mu \mathrm{M}$ of olaparib already suppresses all detectable PARylation (at least, as it is detectable by Western blotting; it is theoretically possible that a small residual PARylation still remains and the method used does not have sufficient sensitivity to detect it, and to inhibit this residual PARP activity, one requires higher concentrations of olaparib). The same concentration of olaparib $(1 \mu \mathrm{M})$ was also sufficient to fully restore cellular $\mathrm{NAD}^{+}$levels to near-normal levels in oxidatively challenged cells. At the $1 \mu \mathrm{M}$ olaparib concentration, cells were also protected from the decline in MTT conversion (an index of mitochondrial function and cell viability). At the lowest tested olaparib concentration $(1 \mu \mathrm{M})$, as well as 3 and 10 times higher $(3 \mu \mathrm{M}$ and $10 \mu \mathrm{M})$, olaparib exerted no adverse effects on mitochondrial or nuclear DNA integrity in normal cells or in oxidatively stressed cells: neither acutely (at $1 \mathrm{~h}$ ) or later (at $24 \mathrm{~h}$ ). At the $24 \mathrm{~h}$ time point—when the cells exhibited a significant degree of nuclear DNA damage, the highest concentrations of olaparib tested $(30 \mu \mathrm{M}$ and $100 \mu \mathrm{M}$ ) — but not the lower concentrations of olaparibinduced a further impairment of nuclear DNA integrity, perhaps indicating that these concentrations of the drug (while commonly used in the oncological context) are to be avoided in the therapeutic repurposing/pancreatitis context. (Nevertheless, please note that in this experiment, the majority of the nuclear DNA damage was induced by $\mathrm{H}_{2} \mathrm{O}_{2}$ per se, and not by the addition of olaparib.) When considering PARP inhibitors' effects on DNA integrity, it should also be mentioned that - the method used here to estimate DNA integrity or DNA damage does not assess all forms of DNA damage (for instance, it does not measure DNA base modifications, or larger scale aberrations like micronucleus instability or chromosomal alterations) (55). To assess the effect of olaparib on these parameters, further studies are required.

The current experimental design utilized a relatively shortterm model, where longer-term events (e.g., later-time mortality) was not evaluated. This is a clear limitation of the current report Nevertheless, it should be noted that in other models of critical illness (e.g., cecal ligation and puncture induced polymicrobial septic shock), olaparib treatment, in fact, had significant beneficial effects on a variety of parameters including organ injury as well as mortality (27).

Taken together, on the results of the current studies, we conclude that the clinically approved PARP inhibitor olaparib can improve organ function and can exert beneficial effects in pancreatitis and its efficacy can be demonstrated both in male and female animals. Based on the results of the in vitro experiments, we can also predict that there are concentrations of olaparib (e.g., $1 \mu \mathrm{M}$ ) at which the PARP inhibitor exerts beneficial and cytoprotective effects without adversely affecting cell viability or nuclear or mitochondrial DNA integrity. Taken together, the current results support the concept of repurposing and clinical introduction of this PARP inhibitor for the experimental therapy of pancreatitis. This conclusion is further strengthened by our data demonstrating that in pancreatitis (both acute and chronic forms) similar to a variety of other forms of critical illness including sepsis $(56,57)$-increased accumulation of PAR (the product of PARP) occurs.

\section{REFERENCES}

1. Kambhampati S, Park W, Habtezion A: Pharmacologic therapy for acute pancreatitis. World J Gastroenterol 20:16868-16880, 2014.

2. Gapp J, Hall AG, Walters RW, Jahann D, Kassim T, Reddymasu S: Trends and outcomes of hospitalizations related to acute pancreatitis: epidemiology from 2001 to 2014 in the United States. Pancreas 48:548-554, 2019.

3. Bi Y, Atwal T, Vege SS: Drug therapy for acute pancreatitis. Curr Treat Options Gastroenterol 13:354-368, 2015

4. Jagtap P, Szabo C: Poly(ADP-ribose) polymerase and the therapeutic effects of its inhibitors. Nat Rev Drug Discov 4:421-440, 2005.

5. Ba X, Garg NJ: Signaling mechanism of poly(ADP-ribose) polymerase-1 (PARP-1) in inflammatory diseases. Am J Pathol 178:946-955, 2011.

6. Bai P, Virág L: Role of poly(ADP-ribose) polymerases in the regulation of inflammatory processes. FEBS Lett 586:3771-3777, 2012.

7. Curtin NJ, Szabo C: Therapeutic applications of PARP inhibitors: anticancer therapy and beyond. Mol Aspects Med 34:1217-1256, 2013.

8. Brunyanszki A, Szczesny B, Virág L, Szabo C: Mitochondrial poly(ADP-ribose) polymerase: the Wizard of $\mathrm{Oz}$ at work. Free Radic Biol Med 100:257-270, 2016.

9. Sethi GS, Dharwal V, Naura AS: Poly(ADP-ribose)polymerase-1 in lung inflammatory disorders: a review. Front Immunol 8:1172, 2017.

10. Henning RJ, Bourgeois M, Harbison RD: Poly(ADP-ribose) polymerase (PARP) and PARP inhibitors: mechanisms of action and role in cardiovascular disorders. Cardiovasc Toxicol 18:493-506, 2018.

11. Mota RA, Sánchez-Bueno F, Saenz L, Hernández-Espinosa D, Jimeno J, Tornel PL, Martínez-Torrano A, Ramírez P, Parrilla P, Yélamos J: Inhibition of poly(ADP-ribose) polymerase attenuates the severity of acute pancreatitis and associated lung injury. Lab Invest 85:1250-1262, 2005.

12. Mazzon E, Genovese T, Di Paola R, Muià C, Crisafulli C, Malleo G, Esposito E, Meli R, Sessa E, Cuzzocrea S: Effects of 3-aminobenzamide, an inhibitor of poly (ADP-ribose) polymerase, in a mouse model of acute pancreatitis induced by cerulein. Eur J Pharmacol 549:149-156, 2006.

13. Mota R, Sánchez-Bueno F, Berenguer-Pina JJ, Hernández-Espinosa D, Parrilla P, Yélamos J: Therapeutic treatment with poly(ADP-ribose) polymerase inhibitors attenuates the severity of acute pancreatitis and associated liver and lung injury. Br J Pharmacol 151:998-1005, 2007.

14. Yasar M, Uysal B, Kaldirim U, Oztas Y, Sadir S, Ozler M, Topal T, Coskun O, Kilic A, Cayci T, et al.: Poly(ADP-ribose) polymerase inhibition modulates experimental acute necrotizing pancreatitis-induced oxidative stress, bacterial translocation and neopterin concentrations in rats. Exp Biol Med (Maywood) 235:1126-1133, 2010

15. Yu J, Deng W, Wang W, Ding Y, Jin H, Chen C, Chen X, Xiong X, Xu S: Inhibition of poly(ADP-ribose) polymerase attenuates acute kidney injury in sodium taurocholate-induced acute pancreatitis in rats. Pancreas 41:12991305,2012

16. Yu J, Zuo T, Deng W, Shi Q, Ma P, Chen C, Zhao L, Zhao K, Wang W: Poly(ADP-ribose) polymerase inhibition suppresses inflammation and promotes recovery from adrenal injury in a rat model of acute necrotizing pancreatitis. BMC Gastroenterol 16:81, 2016.

17. Martínez-Bosch N, Fernández-Zapico ME, Navarro P, Yélamos J: Poly(ADPribose) polymerases: new players in the pathogenesis of exocrine pancreatic diseases. Am J Pathol 186:234-241, 2016.

18. Bochum S, Berger S, Martens UM: Olaparib. Recent Results Cancer Res 211:217-233, 2018.

19. Sulai NH, Tan AR: Development of poly(ADP-ribose) polymerase inhibitors in the treatment of BRCA-mutated breast cancer. Clin Adv Hematol Oncol 16:491-501, 2018.

20. Berger NA, Besson VC, Boulares AH, Bürkle A, Chiarugi A, Clark RS, Curtin NJ, Cuzzocrea S, Dawson TM, Dawson VL, et al.: Opportunities for the repurposing of PARP inhibitors for the therapy of non-oncological diseases. Br J Pharmacol 175:192-222, 2018.

21. Xu JC, Fan J, Wang X, Eacker SM, Kam TI, Chen L, Yin X, Zhu J, Chi Z, Jiang $\mathrm{H}$, et al.: Cultured networks of excitatory projection neurons and inhibitory interneurons for studying human cortical neurotoxicity. Sci Transl Med 8:333ra48, 2016.

22. Teng F, Zhu L, Su J, Zhang X, Li N, Nie Z, Jin L: Neuroprotective effects of poly(ADP-ribose)polymerase inhibitor olaparib in transient cerebral ischemia. Neurochem Res 41:1516-1526, 2016.

23. Kapoor K, Singla E, Sahu B, Naura AS: PARP inhibitor, olaparib ameliorates acute lung and kidney injury upon intratracheal administration of LPS in mice. Mol Cell Biochem 400:153-162, 2015.

24. Korkmaz-Icöz S, Szczesny B, Marcatti M, Li S, Ruppert M, Lasitschka F, Loganathan S, Szabó C, Szabó G: Olaparib protects cardiomyocytes against 
oxidative stress and improves graft contractility during the early phase after heart transplantation in rats. Br J Pharmacol 175:246-261, 2018.

25. Mukhopadhyay P, Horváth B, Rajesh M, Varga ZV, Gariani K, Ryu D, Cao Z, Holovac E, Park O, Zhou Z, et al.: PARP inhibition protects against alcoholic and non-alcoholic steatohepatitis. J Hepatol 66:589-600, 2017.

26. Ahmad A, Olah G, Herndon DN, Szabo C: The clinically used PARP inhibitor olaparib improves organ function, suppresses inflammatory responses and accelerates wound healing in a murine model of third-degree burn injury. $\mathrm{Br}$ J Pharmacol 175:232-245, 2018.

27. Ahmad A, de Camargo Vieira J, de Mello AH, de Lima TM, Ariga SK, Barbeiro DF, Barbeiro HV, Szczesny B, Törö G, Druzhyna N, et al. The PARP inhibitor olaparib exerts beneficial effects in mice subjected to cecal ligature and puncture and in cells subjected to oxidative stress without impairing DNA integrity: a potential opportunity for repurposing a clinically used oncological drug for the experimental therapy of sepsis. Pharmacol Res 145:104263, 2019.

28. Ahmad A, Olah G, Szczesny B, Wood ME, Whiteman M, Szabo C: AP39, a mitochondrially targeted hydrogen sulfide donor, exerts protective effects in renal epithelial cells subjected to oxidative stress in vitro and in acute renal injury in vivo. Shock 45:88-97, 2016.

29. Szczesny B, Marcatti M, Ahmad A, Montalbo M, Brunyanszki A, Bibli SI, Papapetropoulos A, Szabo C: Mitochondrial DNA damage and subsequent activation of Z-DNA binding protein 1 link oxidative stress to inflammation in epithelial cells. Sci Rep 8:914, 2018.

30. Mabley JG, Horváth EM, Murthy KG, Zsengellér Z, Vaslin A, Benko R, Kollai M, Szabó C: Gender differences in the endotoxin-induced inflammatory and vascular responses: potential role of poly(ADP-ribose) polymerase activation. $J$ Pharmacol Exp Ther 315:812-820, 2005.

31. Thorsell AG, Ekblad T, Karlberg T, Löw M, Pinto AF, Trésaugues L, Moche M, Cohen MS, Schüler H: Structural basis for potency and promiscuity in poly(ADP-ribose) polymerase (PARP) and tankyrase inhibitors. J Med Chem 60:1262-1271, 2017.

32. Szabo C, Zingarelli B, O'Connor M, Salzman AL: DNA strand breakage, activation of poly (ADP-ribose) synthetase, and cellular energy depletion are involved in the cytotoxicity of macrophages and smooth muscle cells exposed to peroxynitrite. Proc Natl Acad Sci USA 93:1753-1758, 1996

33. Módis K, Gero D, Erdélyi K, Szoleczky P, DeWitt D, Szabo C: Cellular bioenergetics is regulated by PARP1 under resting conditions and during oxidative stress. Biochem Pharmacol 83:633-643, 2012.

34. Szczesny B, Brunyanszki A, Olah G, Mitra S, Szabo C: Opposing roles of mitochondrial and nuclear PARP1 in the regulation of mitochondrial and nuclear DNA integrity: implications for the regulation of mitochondrial function. Nucleic Acids Res 42:13161-13173, 2014.

35. Senra JM, Telfer BA, Cherry KE, McCrudden CM, Hirst DG, O'Connor MJ, Wedge SR, Stratford IJ: Inhibition of PARP-1 by olaparib (AZD2281) increases the radiosensitivity of a lung tumor xenograft. Mol Cancer Ther 10:1949-1958, 2011.

36. To C, Kim EH, Royce DB, Williams CR, Collins RM, Risingsong R, Sporn MB Liby KT: The PARP inhibitors, veliparib and olaparib, are effective chemopreventive agents for delaying mammary tumor development in BRCA1-deficient mice. Cancer Prev Res (Phila) 7:698-707, 2014.

37. Henneman L, van Miltenburg MH, Michalak EM, Braumuller TM, Jaspers JE, Drenth AP, de Korte-Grimmerink R, Gogola E, Szuhai K, Schlicker A, et al. Selective resistance to the PARP inhibitor olaparib in a mouse model for BRCA1-deficient metaplastic breast cancer. Proc Natl Acad Sci USA 112:8409-8414, 2015.

38. Kivlin CM, Watson KL, Al Sannaa GA, Belousov R, Ingram DR, Huang KL, May CD, Bolshakov S, Landers SM, Kalam AA, et al.: Poly (ADP) ribose polymerase inhibition: a potential treatment of malignant peripheral nerve sheath tumor. Cancer Biol Ther 17:129-138, 2016.

39. George E, Kim H, Krepler C, Wenz B, Makvandi M, Tanyi JL, Brown E, Zhang $\mathrm{R}$, Brafford $\mathrm{P}$, Jean $\mathrm{S}$, et al.: A patient-derived-xenograft platform to study BRCA-deficient ovarian cancers. JCI Insight 2:e89760, 2017.

40. Rottenberg S, Jaspers JE, Kersbergen A, van der Burg E, Nygren AO, Zander SA, Derksen PW, de Bruin M, Zevenhoven J, Lau A, et al.: High sensitivity of
BRCA1-deficient mammary tumors to the PARP inhibitor AZD2281 alone and in combination with platinum drugs. Proc Natl Acad Sci USA 105:1707917084, 2008

41. Weston VJ, Oldreive CE, Skowronska A, Oscier DG, Pratt G, Dyer MJ, Smith G, Powell JE, Rudzki Z, Kearns P, et al.: The PARP inhibitor olaparib induces significant killing of ATM-deficient lymphoid tumor cells in vitro and in vivo. Blood 116:4578-4587, 2010.

42. Sun K, Mikule K, Wang Z, Poon G, Vaidyanathan A, Smith G, Zhang ZY, Hanke J, Ramaswamy S, Wang J: A comparative pharmacokinetic study of PARP inhibitors demonstrates favorable properties for niraparib efficacy in preclinical tumor models. Oncotarget 9:37080-37096, 2018.

43. Evers B, Drost R, Schut E, de Bruin M, van der Burg E, Derksen PW, Holstege H, Liu X, van Drunen E, Beverloo HB, et al.: Selective inhibition of BRCA2deficient mammary tumor cell growth by AZD2281 and cisplatin. Clin Cancer Res 14:3916-3925, 2008.

44. van Vuurden DG, Hulleman E, Meijer OL, Wedekind LE, Kool M, Witt H, Vandertop PW, Würdinger T, Noske DP, Kaspers GJ, et al.: PARP inhibition sensitizes childhood high grade glioma, medulloblastoma and ependymoma to radiation. Oncotarget 2:984-996, 2011.

45. Norris RE, Adamson PC, Nguyen VT, Fox E: Preclinical evaluation of the PARP inhibitor, olaparib, in combination with cytotoxic chemotherapy in pediatric solid tumors. Pediatr Blood Cancer 61:145-150, 2014.

46. Deben C, Lardon F, Wouters A, Op de Beeck K, Van den Bossche J, Jacobs J, Van Der Steen N, Peeters M, Rolfo C, Deschoolmeester V, et al.: APR-246 (PRIMA-1(MET)) strongly synergizes with AZD2281 (olaparib) induced PARP inhibition to induce apoptosis in non-small cell lung cancer cell lines. Cancer Lett 375:313-322, 2016.

47. Nile DL, Rae C, Hyndman IJ, Gaze MN, Mairs RJ: An evaluation in vitro of PARP-1 inhibitors, rucaparib and olaparib, as radiosensitisers for the treatment of neuroblastoma. BMC Cancer 16:621, 2016.

48. Marijon H, Lee DH, Ding L, Sun H, Gery S, de Gramont A, Koeffler HP: Co-targeting poly(ADP-ribose) polymerase (PARP) and histone deacetylase (HDAC) in triple-negative breast cancer: higher synergism in BRCA mutated cells. Biomed Pharmacother 99:543-551, 2018.

49. Shen A, Kim HJ, Oh GS, Lee SB, Lee SH, Pandit A, Khadka D, Choe SK, Kwak SC, Yang SH, et al.: NAD+ augmentation ameliorates acute pancreatitis through regulation of inflammasome signalling. Sci Rep 7:3006, 2017.

50. Inal V, Mas MR, Isik AT, Comert B, Aydn S, Mas N, Deveci MS, Tasci I, Yamanel L, Cinar E, et al.: A new combination therapy in severe acute pancreatitis-hyperbaric oxygen plus 3-aminobenzamide: an experimental study. Pancreas 44:326-330, 2015.

51. Virág L, Szabo C: The therapeutic potential of poly(ADP-ribose) polymerase inhibitors. Pharmacol Rev 54:375-429, 2002.

52. Cook SA, Tinker AV. PARP inhibitors and the evolving landscape of ovarian cancer management: a review. BioDrugs 33:255-273, 2019.

53. Hengel SR, Spies MA, Spies M: Small-molecule inhibitors targeting DNA repair and DNA repair deficiency in research and cancer therapy. Cell Chem Biol 24:1101-1119, 2017.

54. Gupte R, Liu Z, Kraus WL: PARPs and ADP-ribosylation: recent advances linking molecular functions to biological outcomes. Genes Dev 31:101-126, 2017.

55. Ayala-Torres S, Chen Y, Svoboda T, Rosenblatt J, Van Houten B: Analysis of gene-specific DNA damage and repair using quantitative PCR. Methods 22:135-147, 2000.

56. Soriano FG, Nogueira AC, Caldini EG, Lins MH, Teixeira AC, Cappi SB, Lotufo PA, Bernik MM, Zsengellér Z, Chen M, et al.: Potential role of poly(adenosine 5'-diphosphate-ribose) polymerase activation in the pathogenesis of myocardial contractile dysfunction associated with human septic shock. Crit Care Med 34:1073-1079, 2006.

57. Pacher P, Szabo C: Role of the peroxynitrite-poly(ADP-ribose) polymerase pathway in human disease. Am J Pathol 173:2-13, 2008. 